\title{
EFFECT OF CURING BATH CONDITIONS ON THE MORPHOLOGY AND STRUCTURE OF POLY(HIGH INTERNAL PHASE EMULSION) FIBERS
}

by

\section{XUEHUI GONG}

Submitted in partial fulfillment of the requirements for the

degree of Master of Science

Department of Chemical and Biomolecular Engineering

CASE WESTERN RESERVE UNIVERSITY

August, 2017 


\section{CASE WESTERN RESERVE UNIVERSITY SCHOOL OF GRADUATE STUDIES}

We hereby approve the thesis of

\section{XUEHUI GONG}

candidate for the Master of Science degree

Committee Chair

\section{Prof. Donald Feke}

Committee Member

Prof. Ica Manas-Zloczower

Committee Member

\section{Prof. Uziel Landau}

Date of Defense

$5 / 12 / 2017$

*We also certify that written approval has been obtained for any proprietary material contained therein. 


\section{Table of Contents}

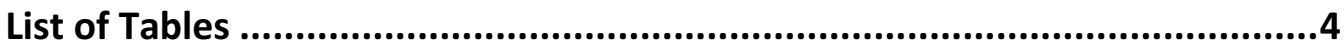

List of Figures ..............................................................................5

Acknowledgements: .......................................................................

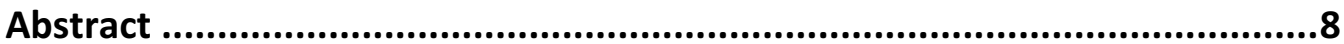

Chapter 1: Introduction .........................................................................9

1-1: Poly(high internal phase emulsion)s ..........................................................9

1-2: Poly(HIPE) Fibers - using HIPEs as a promising starting material to fabricate

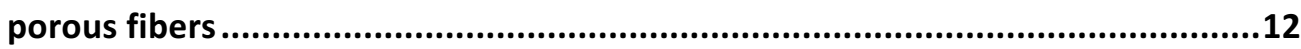

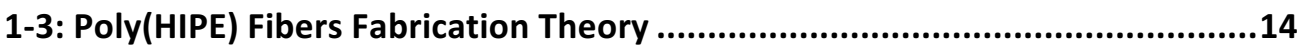

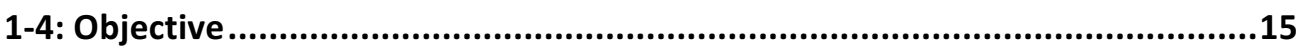

Chapter 2: Experimental Methodology .................................................16

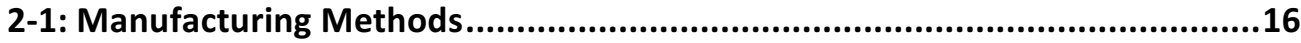

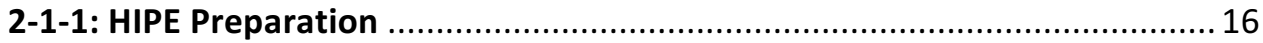

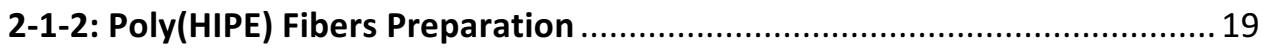

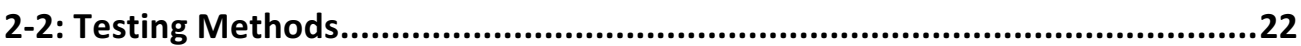

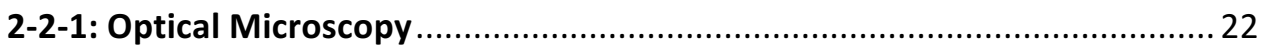

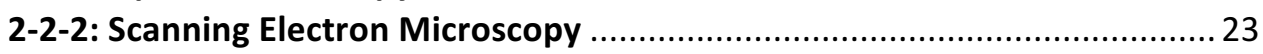

Chapter 3: Effect of Curing Bath Conditions on the Diameter of Poly(HIPE)

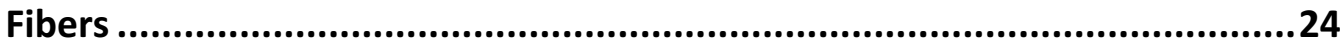

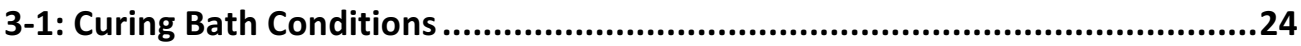

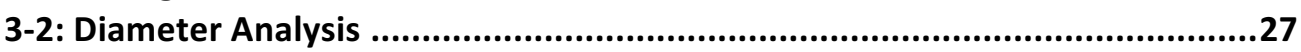

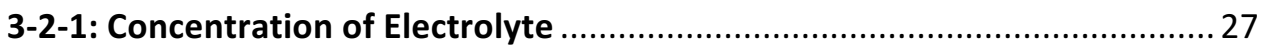

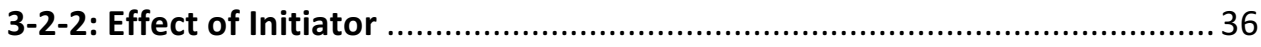

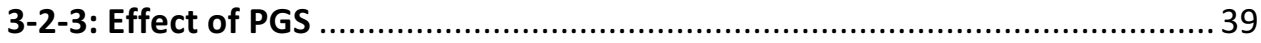

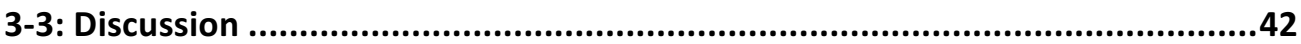

Chapter 4: Effect of Curing Bath Conditions on the Morphology of Poly(HIPE)

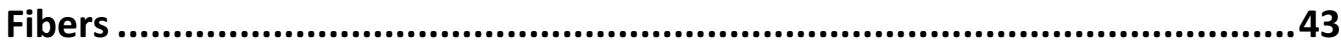

4-1: Morphology Study of Poly(HIPE)s Fiber Surface .........................................43

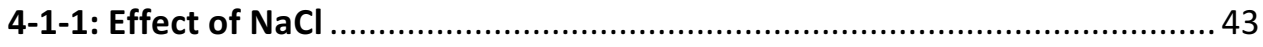

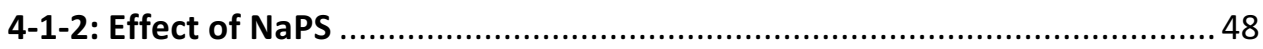

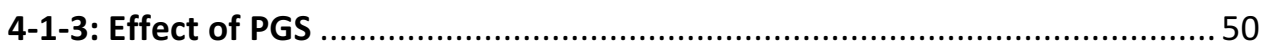

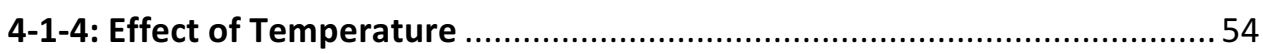

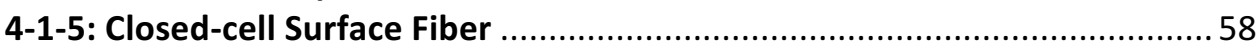

4-2: Morphology Study of Poly(HIPE) Fibers Cross-section .................................62

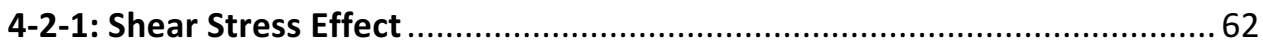

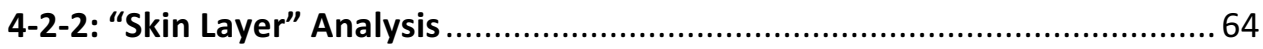

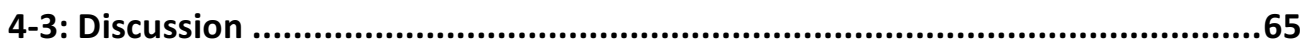

Chapter 5: Conclusions and Future Works ........................................67

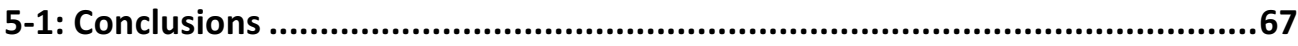

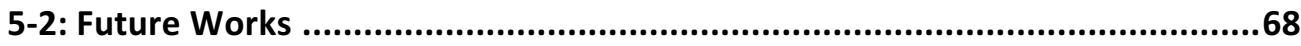


Chapter 6: References .......................................................................69 


\section{List of Tables}

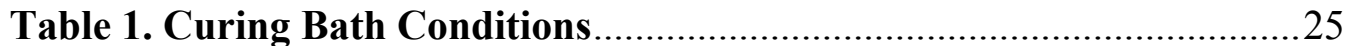

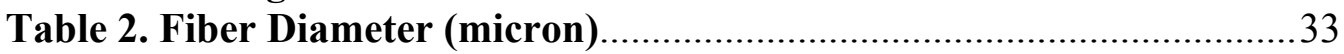

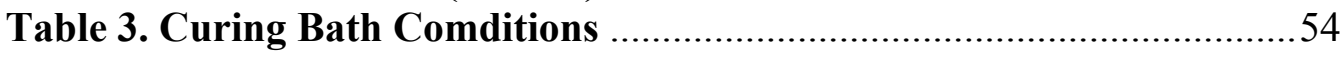

Table 4. Poly(HIPE) Fibers Surface Openness .........................................66 


\section{List of Figures}

Figure 1-1: Schematic of the formation of high internal phase emulsions. An aqueous phase (shown in blue) is continuously added and mixed into an oil phase (the orange region) until most of the emulsion volume is occupied by droplets of the aqueous phase.

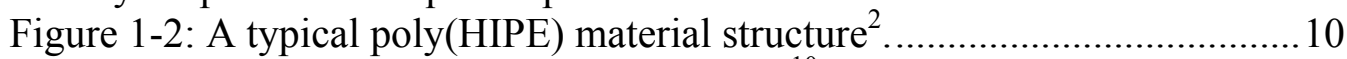

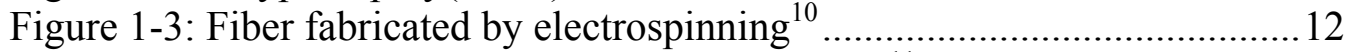

Figure 1-4: Schematic of the electrospinning process ${ }^{11}$................................ 13

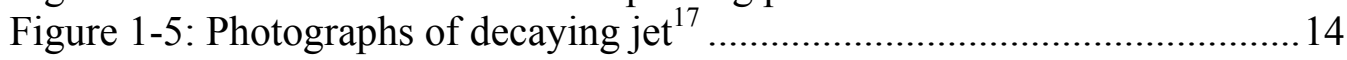

Figure 2-1: The monomers utilized in HIPEs............................................. 16

Figure 2-2: The water circulator system used to heat the aqueous phase and add

it into the HIPE mixing vessel. ................................................................ 18

Figure 2-3: The overhead mixer and the 500ml HIPE mixing vessel............... 18

Figure 2-4: Syringe with needle used for injecting HIPE into the curing bath.. 19

Figure 2-5: (Left) Curing bath used in the experiments, (right) Soxhlet

apparatus used to wash poly(HIPE) fibers.........................................20

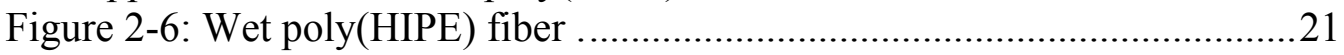

Figure 2-7: Dry poly(HIPE) fibers......................................................... 21

Figure 3-1: Poly(HIPE) fiber diameter change under the effect of electrolyte in

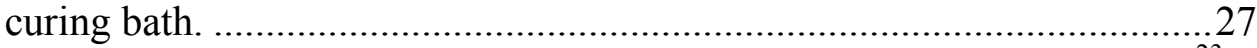

Figure 3-2: Osmotic pressure as a function of solution concentration at $25^{\circ} \mathrm{C}^{23}$.

Figure 3-3: A schematic representation of poly(HIPE) fiber expansion. ...........30

Figure 3-4: A schematic representation of poly(HIPE) fiber shrinkage............ 30

Figure 3-5: HIPE injected into different curing baths at room temperature (left)

pure $\mathrm{DI}$, (right) $5 \mathrm{wt} \% \mathrm{NaCl}$ solvent.;(above top) just after injection,

(below bottom) 24h later....................................................................... 32

Figure 3-6: Wet poly(HIPE) fiber diameter changes under the effect of

electrolyte concentration in the curing bath and the storage bath..............33

Figure 3-7: Poly(HIPE) fiber cured in DI water........................................... 35

Figure 3-8: Poly(HIPE) fiber diameter changes under the effect of initiator concentration in the curing bath.......................................................... 36

Figure 3-9: Poly(HIPE) fiber diameter change under the effect of surfactant

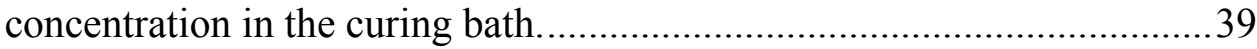

Figure 3-10: Poly(HIPE) fiber diameter change under the effect of surfactant and electrolyte concentrations in the curing bath. ................................. 40

Figure 3-11: (left) PGS in DI water, (right) PGS in $2 \mathrm{wt} \% \mathrm{NaCl}$.....................4 4

Figure 4-1: Surfaces of pol(HIPE)fibers prepared in different curing baths at $85^{\circ} \mathrm{C}$. Top is DI water; middle is $2 \mathrm{wt} \% \mathrm{NaCl}$; bottom is $5 \mathrm{wt} \% \mathrm{NaCl}$. (Left) fiber surface image, scale bar in 100um (right) high magnification image, scale bar in 10um.

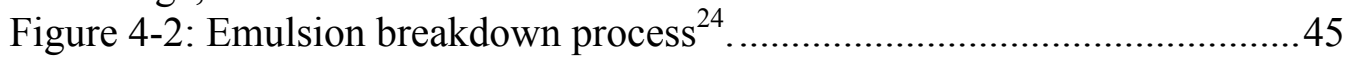

Figure 4-3: Swelling of the poly(HIPE) fiber.......................................... 47

Figure 4-4: The surfaces of fibers prepared in different curing baths at $85^{\circ} \mathrm{C}$.

Top two are DI water; middle $0.33 \mathrm{wt} \% \mathrm{NaPS}$; bottom, $0.33 \mathrm{wt} \% \mathrm{NaPS}$ 
and $2 \mathrm{wt} \% \mathrm{NaCl}$. Left, fiber surface image; right high magnification image.

Figure 4-5: The surfaces of fibers prepared in different curing baths at $85^{\circ} \mathrm{C}$.

Top is $0.1 \mathrm{wt} \%$ PGS; middle is $0.36 \mathrm{wt} \%$ PGS; bottom is $0.63 \mathrm{wt} \%$ PGS.

Figure 4-6: The surfaces of poly(HIPE) fibers prepared in different curing baths at $85^{\circ} \mathrm{C}$. Top is $0.1 \mathrm{wt} \%$ PGS and $2 \mathrm{wt} \% \mathrm{NaC}$, middle is $0.36 \mathrm{wt} \%$ PGS and $2 \mathrm{wt} \% \mathrm{NaCl}$, bottom is $0.63 \mathrm{wt} \% \mathrm{PGS}$ and $2 \mathrm{wt} \% \mathrm{NaCl}$.

Figure 4-7: SEM image of poly(HIPE) fiber surface prepared in different curing baths: a. $95^{\circ} \mathrm{C}$ DI water; b. $85^{\circ} \mathrm{C}$ DI water; c. $95^{\circ} \mathrm{C} 2 \mathrm{wt} \% \mathrm{NaCl}$; d. $85^{\circ} \mathrm{C} 2$ $\mathrm{wt} \% \mathrm{NaCl}$; e. $95^{\circ} \mathrm{C} 5 \mathrm{wt} \% \mathrm{NaCl}$; f. $85^{\circ} \mathrm{C} 5 \mathrm{wt} \% \mathrm{NaCl} \ldots \ldots \ldots \ldots \ldots \ldots \ldots \ldots \ldots . . . .55$

Figure 4-8: SEM image of poly(HIPE) fiber surface prepared in different curing baths. a. $95^{\circ} \mathrm{C} 0.33 \mathrm{wt} \% \mathrm{NaPS}$; b. $85^{\circ} \mathrm{C} 0.33 \mathrm{wt} \% \mathrm{NaPS}$; c. $95^{\circ} \mathrm{C} 0.33 \mathrm{wt} \%$

$\mathrm{NaPS}$ and $2 \mathrm{wt} \% \mathrm{NaCl} ; \mathrm{d} .85^{\circ} \mathrm{C} 0.33 \mathrm{wt} \% \mathrm{NaPS}$ and $2 \mathrm{wt} \% \mathrm{NaCl}$. 56

Figure 4-9: Poly(HIPE) fibers, curing bath $0.66 \mathrm{wt} \% \mathrm{NaPS} 85^{\circ} \mathrm{C}$. a. poly(HIPE) fiber surface morphology $b$. High magnification image (both fiber surface and inside structure) c, d . High magnification surface image with

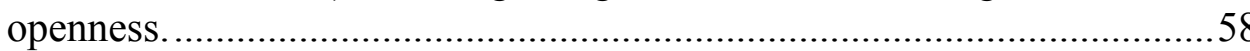

Figure 4-10: Poly(HIPE) fibers, curing bath $0.66 \mathrm{wt} \% \mathrm{NaPS}$. (left) $85^{\circ} \mathrm{C}$, poly(HIPE) fiber surface morphology and high magnification image surface image with openness in below. (right) $95^{\circ} \mathrm{C}$, poly(HIPE) fiber surface morphology and high magnification image surface image. 60

Figure 4-11: Poly(HIPE) fiber cross-section. ....................................................62

Figure 4-12: Poly(HIPE) fiber cross section a. Cured in DI Water at $85^{\circ} \mathrm{C}, \mathrm{b}$. Cured in $2 \mathrm{wt} \% \mathrm{NaCl}$ at $85^{\circ} \mathrm{C}$, c. Cured in $5 \mathrm{wt} \% \mathrm{NaCl}$ at $85^{\circ} \mathrm{C}$ d. High magnification image of fiber cured in $5 \mathrm{wt} \% \mathrm{NaCl}$ at $85^{\circ} \mathrm{C}$. 


\section{Acknowledgements:}

I would like to thank Professors Donald Feke and Ica Manas- Zloczower for being my advisors and help me with my research in the past two years. I would like to thank Professor Uziel Landau for the time and effort in serving on my committee. I would also like to thank Boran Zhao and the mixing group to help me with my research. Finally, I would like to thank our collaborators at Procter \& Gamble for their financial support and technical help throughout the project. 


\title{
Effect of Curing Bath Conditions on the
}

\section{Morphology and Structure of Poly(High Internal}

\author{
Phase Emulsion) Fibers
}

Abstract

by

\section{XUEHUI GONG}

Poly(high internal phase emulsion)s (polyHIPEs) are highly porous materials which have wide application in many fields. In this thesis, the potential of polymerizing high internal phase emulsions (HIPE)s to fabricate porous fibers has been demonstrated. By tuning the composition of the curing bath for the fibers, the openness of the fiber surface can be adjusted. Increasing the curing temperature, electrolyte concentration or initiator concentration in the curing bath leads to the formation of smaller open cells on the fiber surface. Surfactant added to the curing bath can generate large open cells on the fiber surface.

A closed-cell surface on the fiber can be produced by adding a large amount of initiator to the curing bath. Fibers with a small amount of surface pores, which have a length-scale on the order of hundreds nanometers, are formed. Poly(HIPE) fibers with only closed-cell surfaces can also be fabricated under some conditions. 


\section{Chapter 1: Introduction}

\section{1-1: Poly(high internal phase emulsion)s}

High Internal Phase Emulsions (HIPE)s are emulsions whose internal phase volume ratio exceeds the theoretical limit of the maximum packing volume of rigid spheres in a mono-dispersed system, $74 \mathrm{vol} . \%^{1}$. When this value is exceeded, the internal phase droplets will transform from spheres to polyhedra ${ }^{1}$, which enables the formation of a large contact area between nearby droplets. Surfactant is required when a large volume of internal phase is dispersed in a minor amount of continuous external phase in order to stabilize the emulsion by reducing the surface tension between the internal and external phases.

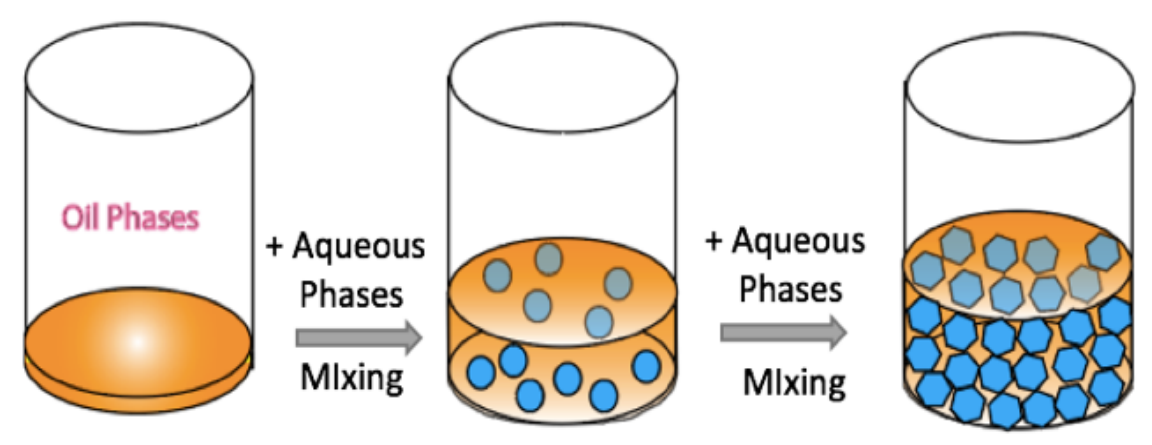

Figure 1-1:Schematic of the formation of high internal phase emulsions. An aqueous phase (shown in blue) is continuously added and mixed into an oil phase (the orange region) until most of the emulsion volume is occupied by droplets of the aqueous phase.

Poly(HIPE)s are formed by polymerizing the monomers and cross-linker in the continuous oil phase of a water-in-oil HIPE. Break up of the thin films 
between the droplets during polymerization generates openings between the neighboring droplets. After removing the dispersed phase within the poly(HIPE)s via evaporation or other process, a highly porous structure is achieved. As Figure 1-2 indicates, the main open spaces where the dispersed phase used to be located are defined as "voids." The small open interconnection areas between voids are called "windows," and these are created by rupture of the organic film separating two nearby droplets in the HIPEs. A distribution of void sizes is observed since coalescence and/or Ostwald ripening ${ }^{3}$ effects either combine two nearby droplets into a large one or form larger droplets from the consumption of smaller droplets during the process of making the HIPEs.

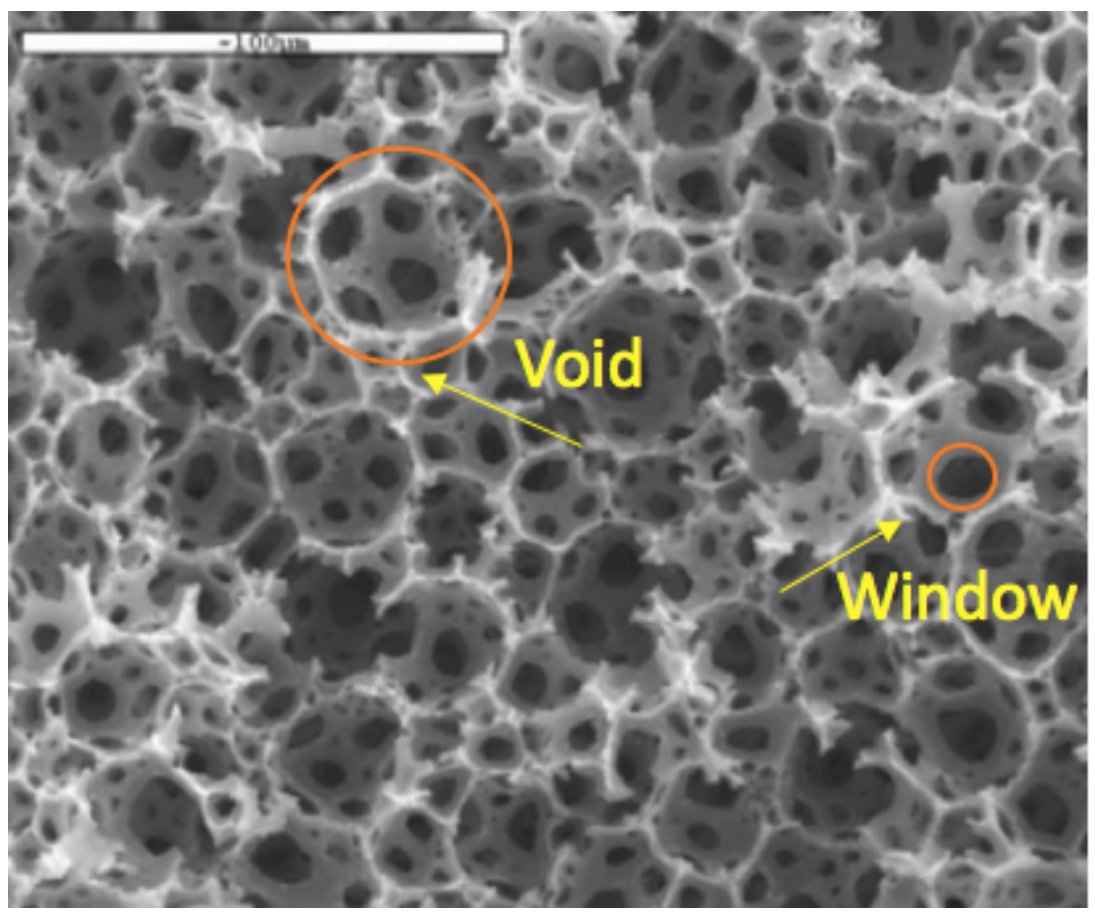

Figure 1-2: A typical poly(HIPE) material structure ${ }^{2}$. 
Due to their high porous structure and large surface area property, poly(HIPE)s have wide application in many fields including being absorption materials, catalyst supports, separation membranes, tissue engineering scaffolds and controlled release matrices, ${ }^{4}$ etc. 


\section{1-2: Poly(HIPE) Fibers - using HIPEs as a promising starting material to}

fabricate porous fibers

Porous fibers have many applications such as a reinforcing component in composite systems ${ }^{5.6}$, membranes for biomedical separations or water treatment, tissue engineering scaffolds ${ }^{7.8}$ as well as components in energy generating fuel cells ${ }^{9}$. Electrospinning has been regarded as an effective approach to produce porous fibers (Figure 1-3). While fabricating fibers with this technology, an electric field stretches a dissolved polymer-solvent jet causing an increase of its length, and the evaporation of solvent during stretching helps generate porous openings in the fiber (Figure 1-4). More creative structures such as hollow or straight fibers can also be generated with additional procedures ${ }^{12}$. Using electrospinning, the fiber diameter can be controlled within a broad range, from microns to a few tens of nanometers ${ }^{13}$.
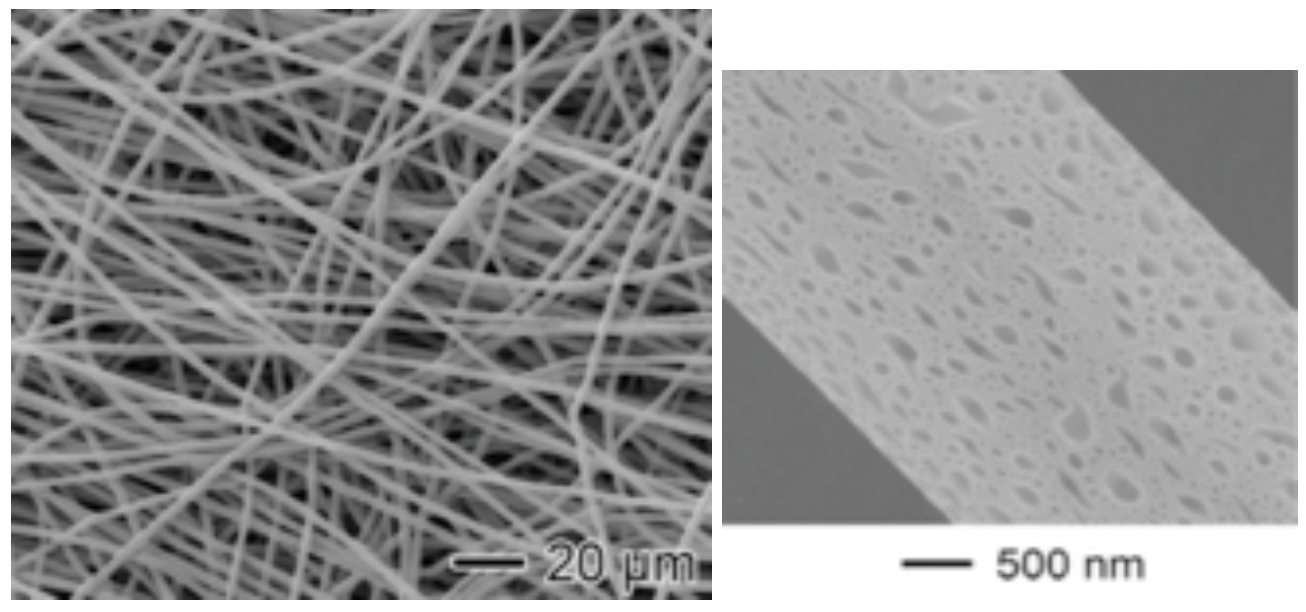

Figure 1-3: Fiber fabricated by electrospinning ${ }^{10}$ 


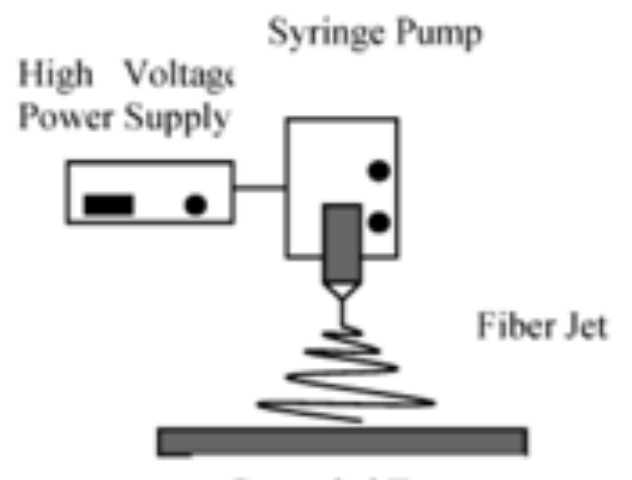

Grounded Target

Figure 1-4: Schematic of the electrospinning process ${ }^{11}$

Well known for its high porosity, poly(HIPE) is now considered as an alternative material for producing porous fibers for its benefits include environmental friendly fabricating procedures compared with electrospinning. When working with electrospinning, evaporation of the organic solvent is required in order to generates porosity of the fibers, but those toxic substances can do harm to the human body as well as doing harm to the environment. For specific applications such as filtration or biomaterial templates, it is desirable to control not only the fiber diameter, but also its internal morphology. Using poly(HIPE) as a replacement material can provide a means to solve those problem. In addition, there is a significant potential for manipulating the fiber morphology and structure by controlling the parameters used in fabricating poly(HIPE) fibers. 


\section{1-3: Poly(HIPE) Fibers Fabrication Theory}

When fabricating fibers by ejecting a liquid stream using a nozzle, there is a tendency for that stream to break up into droplets. This phenomenon is known as Rayleigh instability ${ }^{14}$. However, because the HIPE used in this work has a relatively high viscosity and high yield stress, the instability phenomenon is reduced. The significant yield stress that HIPE possesses retards the destabilizing effects of Rayleigh waves and helps to generate continuous fibers $^{15.16}$.
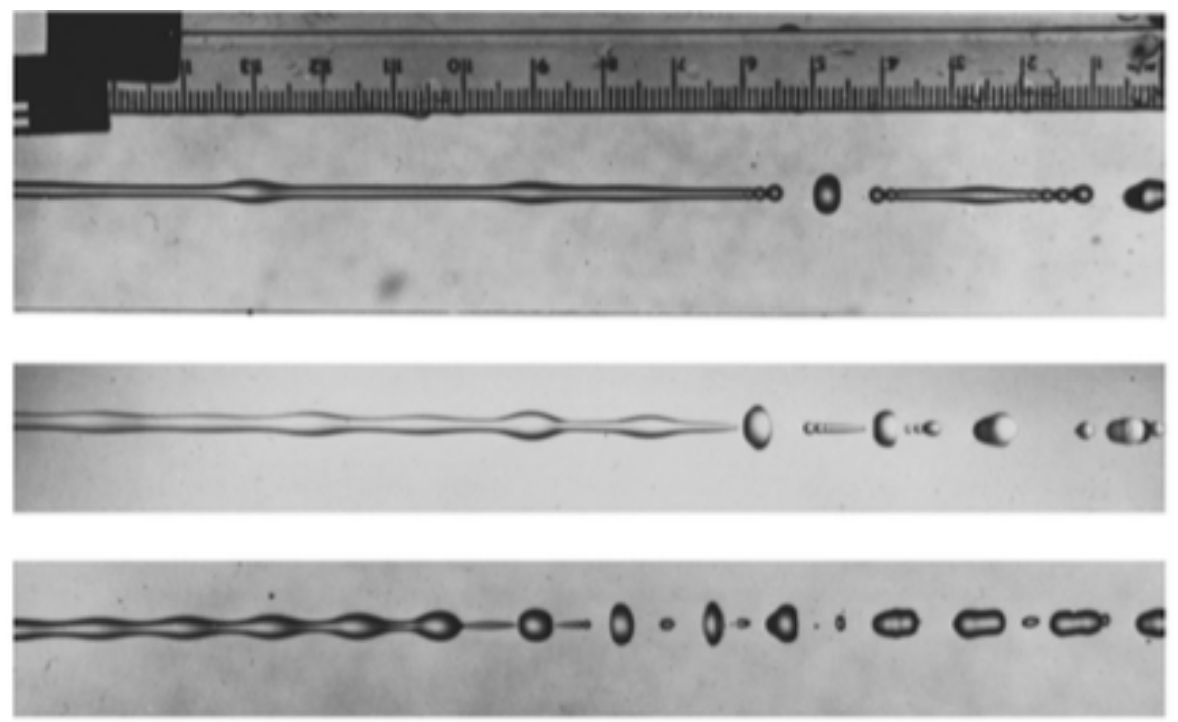

Figure 1-5: Photographs of decaying jet ${ }^{17}$ 


\section{1-4: Objective}

In this project, verifying the potential of using HIPEs as an alternative material to fabricate porous fibers will be the first step. To further study how the curing bath condition can vary the morphology and structure of poly(HIPE) fibers, changing the components added in curing bath will be the next step. When curing HIPE in an aqueous bath, the curing bath will not only provide the thermal energy and outside environment for the polymerization reaction, it can also generate an additional physical influence or chemical reaction which can play a role in changing the poly(HIPE) fiber morphology and structure. More discussions on curing bath conditions will be provided in chapter 3 . 


\section{Chapter 2: Experimental Methodology}

\section{2-1: Manufacturing Methods}

\section{2-1-1: HIPE Preparation}

The HIPEs used in this project are water-in-oil emulsions prepared with the components shown below. The oil phase was composed of 3.35:1 weight ratio of 2-ethylhexyl acrylate (EHA, Sigma Aldrich) to ethylene glycol dimethacrylate (EGDMA, Sigma Aldrich). A 12 wt\%, weight ratio regarding the overall oil phase, polyglycerol succinate (PGS, Procter \& Gamble) was mixed into the oil phase as surfactant. The aqueous phase (the dispersed phase in our emulsion system) was composed of $2 \mathrm{wt} \%$ sodium chloride $(\mathrm{NaCl}$, Fisher Scientific) and 0.33 wt\% sodium persulfate (NaPS, Sigma Aldrich). The waterto-oil weight ratio was 19 to 1 in this project.

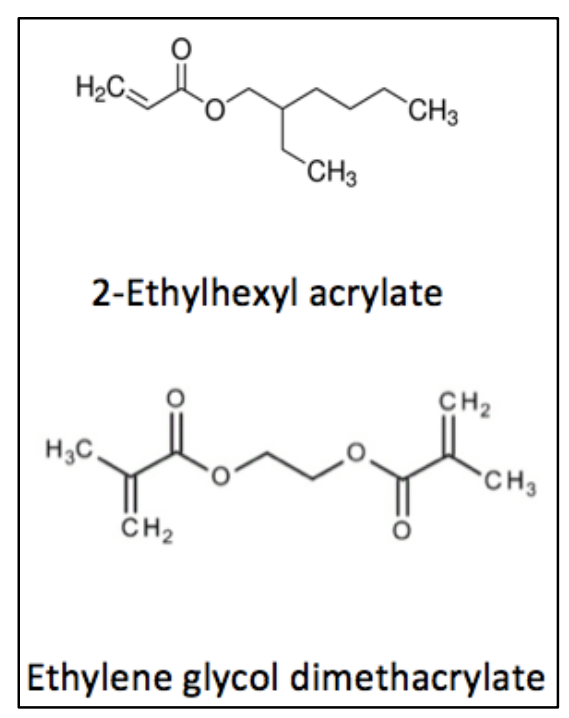

Figure 2-1: The monomers utilized in HIPEs. 
When making 19:1 water-to-oil emulsions, $8 \mathrm{~g}$ of well-mixed oil phase was added into a $500 \mathrm{~mL}$ bottle, and $152 \mathrm{~g}$ of $2 \mathrm{wt} \% \mathrm{NaCl}, 0.33 \mathrm{wt} \% \mathrm{NaPS}$ aqueous solution was added in two steps. The mixture was constantly stirred within a cylindrical vessel (inner diameter $=67.2 \mathrm{~mm}$ ) at $300 \mathrm{rpm}$ by an overhead mixer (IKA) having an impeller diameter of $52.1 \mathrm{~mm}$. In the first 3 minutes and 6 seconds, $142 \mathrm{~g}$ of $2 \mathrm{wt} \% \mathrm{NaCl}$ solution heated to $40^{\circ} \mathrm{C}$ was added at a uniform rate into the $500 \mathrm{ml}$ bottle containing the oil phase. In the following 54 seconds, 0.33 wt\% NaPS (regarding the overall aqueous phase) dissolved in $10 \mathrm{~g}$ of $2 \mathrm{wt} \% \mathrm{NaCl}$ solution was added smoothly into the mixing bottle. Mixing continued for an extra 1 minute. The overall mixing procedure lasts 5 minutes. The mixing time has a great influence on the HIPEs' properties, with longer mixing time resulting in smaller droplets. The mixing procedure used in this project came from Procter \& Gamble according to their research. Parameters such as mixing temperature can be of some effect on the HIPE properties: heating the aqueous phase up to $40^{\circ} \mathrm{C}$ enhances the migration and dispersion of surfactant between oil phase and the aqueous phase which benefits the stability of the emulsion system. 


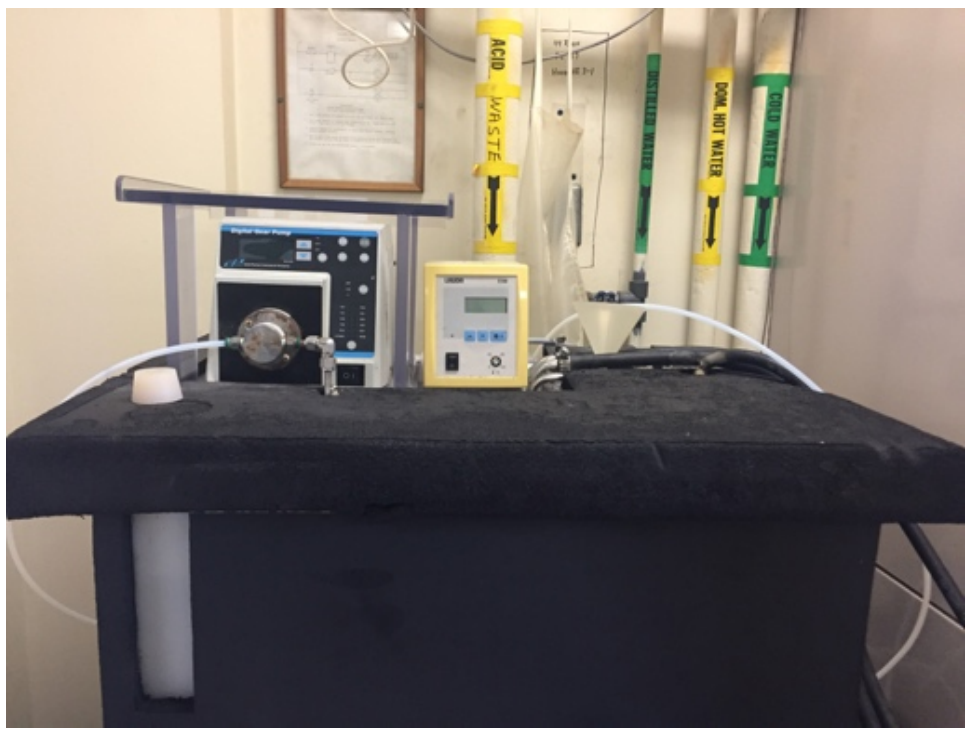

Figure 2-2: The water circulator system used to heat the aqueous phase and add it into the HIPE mixing vessel.

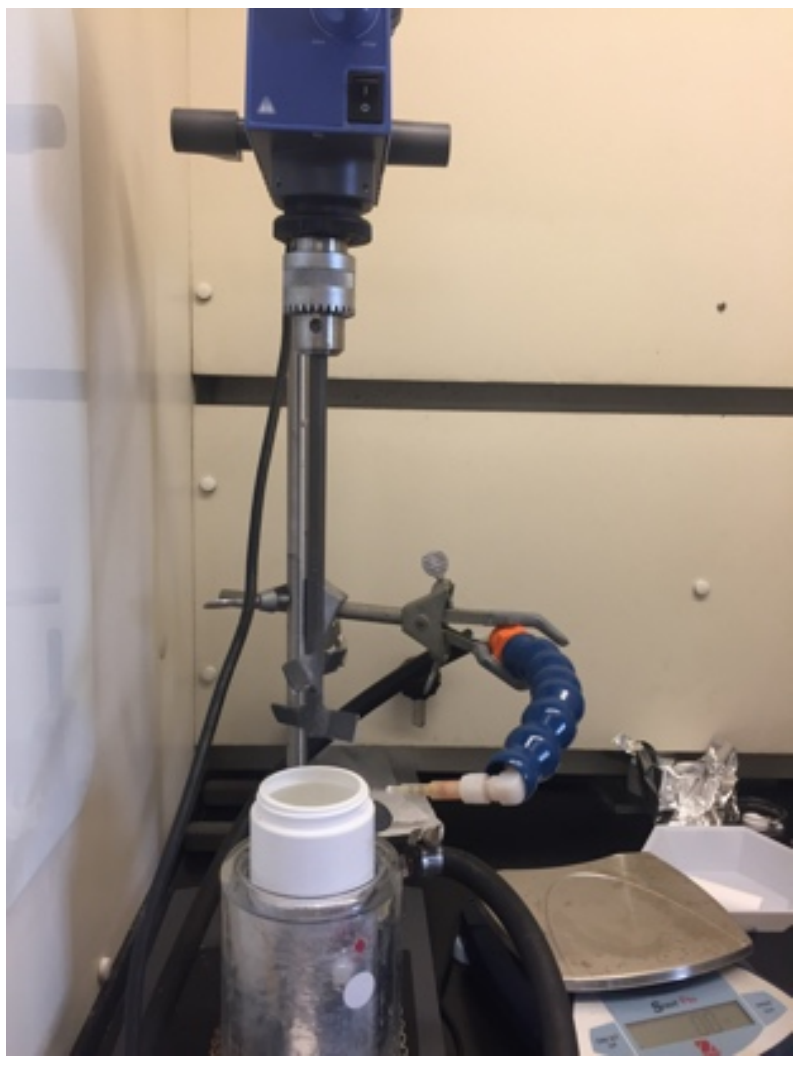

Figure 2-3: The overhead mixer and the 500ml HIPE mixing vessel. 


\section{2-1-2: Poly(HIPE) Fibers Preparation}

The EHA and EGDMA in the oil phase of the HIPEs were polymerized when the initiator NaPS triggers the free- radical polymerization process. EHA is the main monomer and EGDMA acts as crosslinker. After polymerization, the crosslinker provides additional mechanical strength and thermal stability which enables the formation of solid poly(HIPE) fibers. $\mathrm{NaCl}$ and the surfactant PGS play important roles in stabilizing the internal aqueous phase and thereby producing the poly(HIPE)'s highly porous structures ${ }^{18}$. Curing temperatures are chosen as $85^{\circ} \mathrm{C}$ and $95^{\circ} \mathrm{C}$ according to some previous chemorheology research ${ }^{19}$, while the curing time is selected as $20 \mathrm{~min}$ for completely curing the fiber. The syringe used in this project is 18 gauge syringe needle whose inner diameter is $0.838 \mathrm{~mm}$, and the outer diameter is $1.270 \mathrm{~mm}$ according to standard specifications for syringes (Figure 2-4).

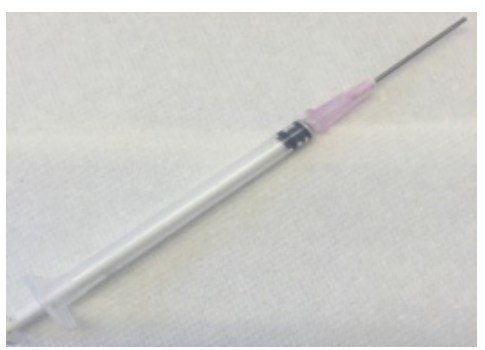

Figure 2-4: Syringe with needle used for injecting HIPE into the curing bath.

The experimental setup for making poly(HIPE) fibers is shown in Figure 2-5. Usually, $1 \mathrm{ml}$ of HIPE is injected at the rate $0.125 \mathrm{~mL} / \mathrm{sec}$ into $100 \mathrm{~g}$ of heated curing bath containing different components to fabricate the 
poly(HIPE) fibers. Details of the curing bath conditions will be well explored in later sections of this thesis. After curing, the poly(HIPE) fibers are extracted from the bath and stored at room temperature (Figure 2-6). Samples are washed using a Soxhlet apparatus with DI water and then isopropanol, each for $24 \mathrm{~h}$, which results in all of the salt and most of the surfactant in the fiber being washed away. Morphology and structure analyses are conducted later with either optical or scanning electron microscopy. Freeze-dried poly(HIPE) fibers (Figure 2-7) were also prepared for scanning electron microscopy.
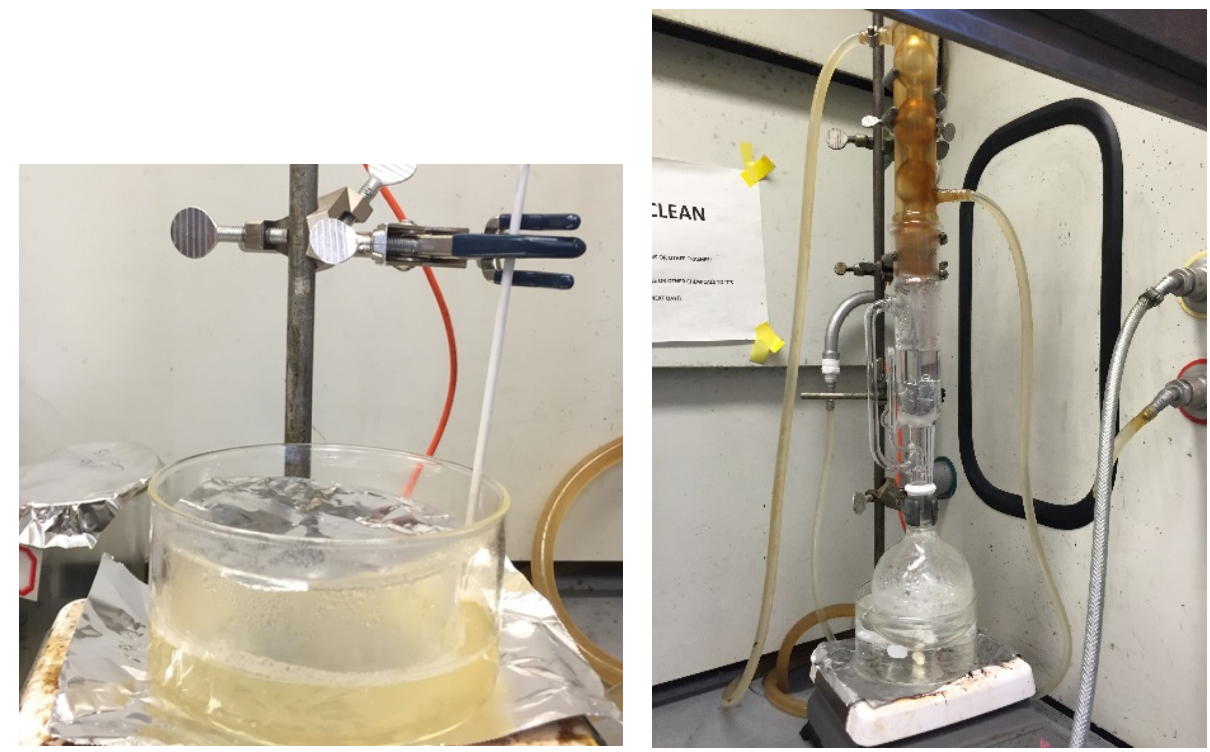

Figure 2-5: (Left) Curing bath used in the experiments, (right) Soxhlet apparatus used to wash poly(HIPE) fibers. 

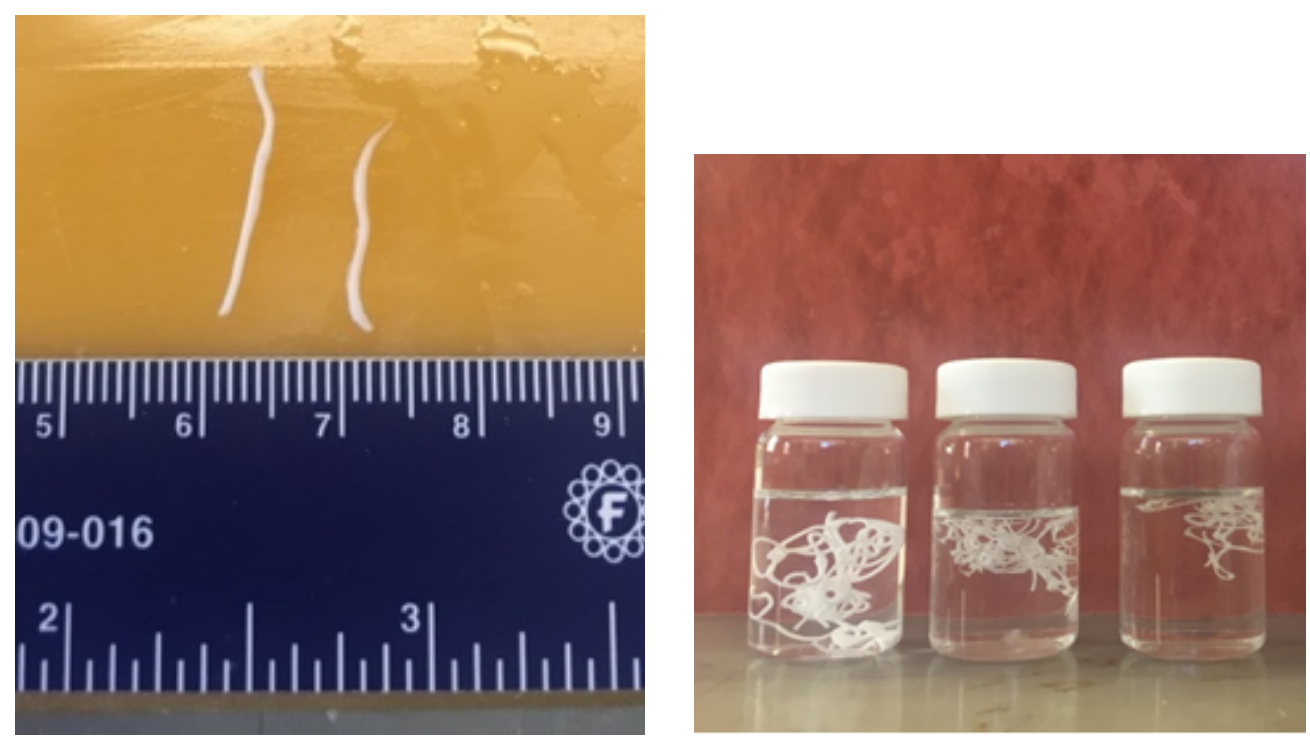

Figure 2-6: Wet poly(HIPE) fiber .
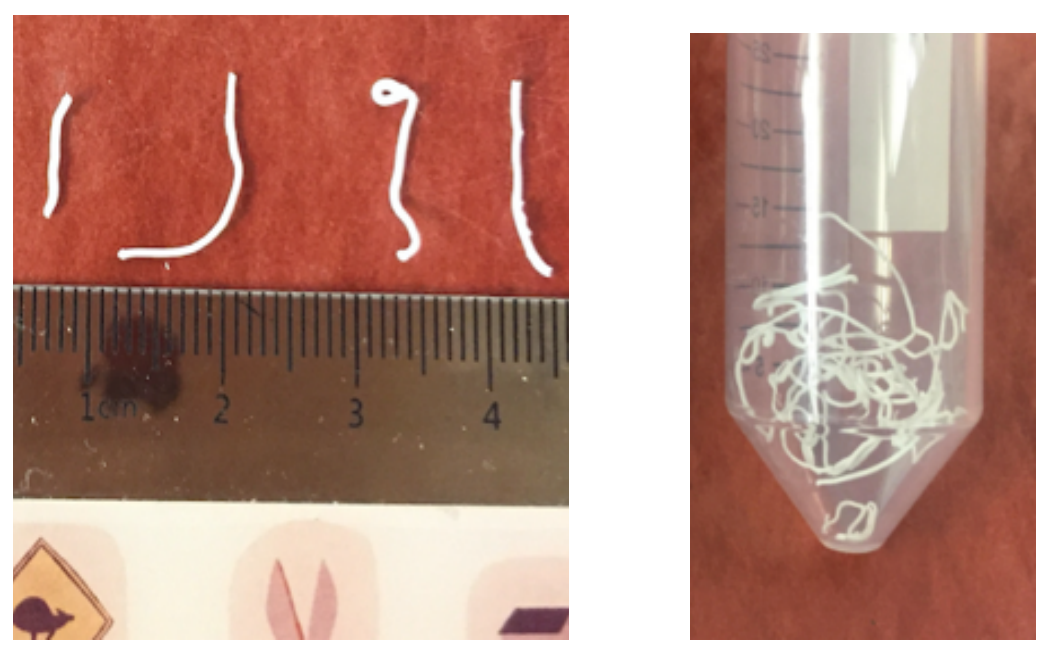

Figure 2-7: Dry poly(HIPE) fibers. 


\section{2-2: Testing Methods}

\section{2-2-1: Optical Microscopy}

Optical microscopy utilizes visible light and a system of lenses to produce magnified images of small samples. In this project, poly(HIPE) fibers prepared using the methods described above were observed and analyzed by optical microscope. Poly(HIPE) fibers cured under different curing bath conditions were inspected by an optical microscope microscope. Since poly(HIPE) fibers are in of reasonable small scale, the fiber diameter analysis was produced with the help of using this equipment. 


\section{2-2-2: Scanning Electron Microscopy}

Scanning electron microscope (SEM) is a useful approach to detect

micro-scale structures, and some can even reach a resolution as small as the nanoscale. When working with poly(HIPE) fibers, diameters are in the range of hundreds of microns, however the void sizes and window sizes can be as low as few microns. After sputter coating, samples were scanned by the focused beam of electrons within the SEM. When electrons interact with the sample, different signals containing surface morphology information were achieved. In this project, SEM analysis provides straightforward morphology and structure results, helping to explore the relationship between morphologies and curing conditions. 


\section{Chapter 3: Effect of Curing Bath Conditions on the Diameter of Poly(HIPE) Fibers}

\section{3-1: Curing Bath Conditions}

In order to explore the polymerization behavior of HIPEs upon injection into the aqueous bath, and to manipulate the fiber structure, different curing baths were prepared by adding different amounts of the components present within the HIPEs: $\mathrm{NaCl}$ (sodium chloride), NaPS (sodium persulfate) and PGS (polyglycerol succinate). Generally speaking, the electrolyte $\mathrm{NaCl}$ plays an important role in controlling the void size and stabilizing the HIPE. By changing the concentration of $\mathrm{NaCl}$ in the curing bath, varied morphologies of the fiber surface were expected NaPS is the initiator that triggers the polymerization of the monomers in the oil phase. By changing the concentration of initiator in the curing bath, polymerization kinetics will be changed. PGS, used as the emulsifier, is responsible for reducing surface tension at the oil-water interface, and thus we also want to explore how PGS in the curing bath can change the poly(HIPE) fibers' characteristics. Table 1 shows eleven different curing bath conditions that were used in the analysis of fiber diameter. The curing temperature for all of these cases was $85^{\circ} \mathrm{C}$. 
Table 1. Curing Bath Conditions

\begin{tabular}{|c|c|}
\hline \multirow{4}{*}{ NaCl Concentration } & DI Water \\
\cline { 2 - 2 } & $2 \mathrm{wt} \% \mathrm{NaCl}$ \\
\cline { 2 - 2 } Initiator & $5 \mathrm{wt} \% \mathrm{NaCl}$ \\
\hline \multirow{4}{*}{ PGS \& DI } & $0.33 \mathrm{wt} \% \mathrm{NaPS}$ \\
\cline { 2 - 2 } & $0.33 \mathrm{wt} \% \mathrm{NaPS}, 2 \mathrm{wt} \% \mathrm{NaCl}$ \\
\cline { 2 - 2 } & $0.1 \mathrm{wt} \% \mathrm{PGS}, \mathrm{DI}$ \\
\cline { 2 - 2 } & $0.36 \mathrm{wt} \% \mathrm{PGS}, \mathrm{DI}$ \\
\hline \multirow{4}{*}{ PGS \& NaCl } & $0.63 \mathrm{wt} \% \mathrm{PGS}, \mathrm{DI}$ \\
\hline & $0.1 \mathrm{wt} \% \mathrm{PGS}, 2 \mathrm{wt} \% \mathrm{NaCl}$ \\
\hline & $0.36 \mathrm{wt} \% \mathrm{PGS}, 2 \mathrm{wt} \% \mathrm{NaCl}$ \\
\hline & $0.63 \mathrm{wt} \% \mathrm{PGS}, 2 \mathrm{wt} \% \mathrm{NaCl}$ \\
\hline
\end{tabular}

In HIPEs, 2 wt\% $\mathrm{NaCl}, 0.33$ wt\% $\mathrm{NaPS}$ (with respect to the aqueous phase) and 12 wt\% PGS (relative to the oil phase) was the standard composition. Using those ratios as a reference, curing bath conditions are listed above. A detailed explanation of the concentration of PGS in the curing baths is shown below. In 19:1 water-to-oil ratio HIPE systems, assuming all the 
PGS in the oil phases is dissolved in the aqueous phase, the aqueous phase will become a solution containing 0.63 wt\% PGS.

$$
\frac{\text { oil phase weight } \times \text { PGS wt } \% \text { in oil phase }}{\text { aqueous phase weight }}=\frac{8 g \times 12 w t \%}{152 g}=0.63 \mathrm{wt} \%
$$

Taking this value as a standard, we choose a relatively low PGS concentration of $0.1 \mathrm{wt} \%$ and an intermediate value of $0.36 \mathrm{wt} \%$ for further exploration. All wet samples were cured and stored in their curing solutions without washing. Dry samples were washed and freeze dried. 


\section{3-2: Diameter Analysis}

\section{3-2-1: Concentration of Electrolyte}

The diameter of the fibers, measured by ImageJ (one kind of

multidimensional image data analysis tool) were found to vary with the $\mathrm{NaCl}$ concentration in the curing bath. Optical microscopy was used to measure the diameter of wet fibers, and SEM was used to provide the freeze-dried fiber diameter values (Figure 3-1).

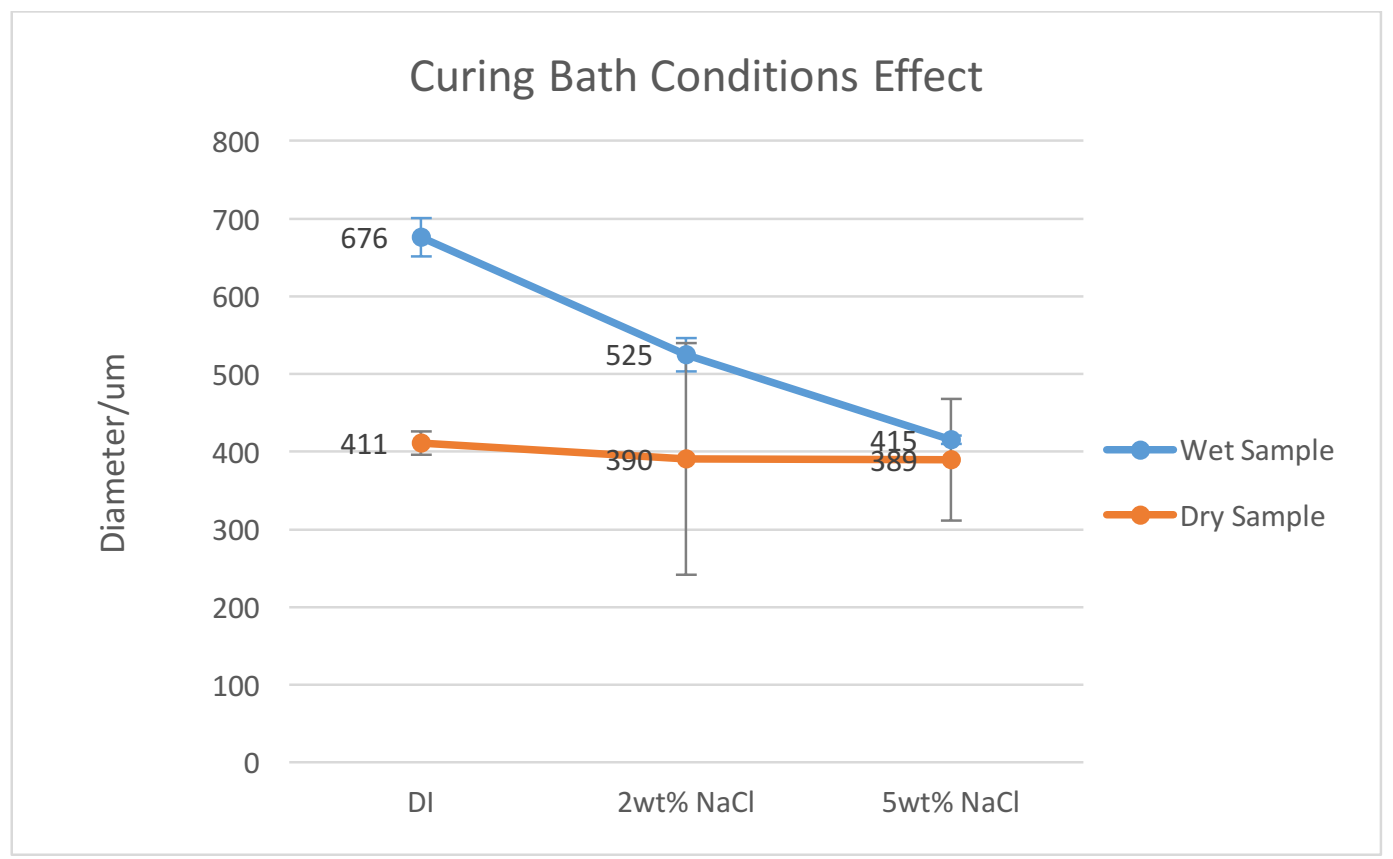

Figure 3-1: Poly(HIPE) fiber diameter change under the effect of electrolyte in curing bath.

For wet samples, the diameter decreases with increasing concentration of $\mathrm{NaCl}$ in curing bath. The osmotic pressure effect caused by the electrolyte 
concentration difference between inside and outside of the fiber is regarded as the principal cause of the variation of the fiber diameter. The $\mathrm{NaCl}$ concentration gap between inside and outside fiber formed by varying the concentration of $\mathrm{NaCl}$ in the curing bath drives water flow in or out of the fibers. When cured in a bath with DI water only, water flows into the fiber causing an increase of water volume in the fiber and thus its diameter since the HIPEs' aqueous phase contained $2 \mathrm{wt} \% \mathrm{NaCl}$. When HIPEs were cured in a bath containing 5 wt\% $\mathrm{NaCl}$, water flow out from fiber into the curing bath decreases the water volume in the fiber, and fiber shrinkage can be observed.

In this section, osmotic pressure was calculated with the Van't Hoff law shown below ${ }^{20.21}$. Relating osmotic pressure to solute concentration, $\pi=i\left[C_{\text {solutes }}\right] R T$, (where $\pi$ is the osmotic pressure, $i$ is a dimensionless correction factor referring to ionization effects (in $\mathrm{NaCl}$ solution, $i=2)$, [ $\left.\mathrm{C}_{\text {solutes }}\right]$ is the molar molecular concentration, $\mathrm{R}$ is the ideal gas constant, and $\mathrm{T}$ is the temperature in degrees Kelvin). The density of the aqueous $\mathrm{NaCl}$ solution was taken as $1 \mathrm{~g} / \mathrm{ml}$.

For 2 wt\% $\mathrm{NaCl}$ :

$$
\pi=2 *[(1000 \times 2) /(58.5 \times 98)] \times 0.082 \times(273+85)=17.05 \mathrm{~atm}
$$

For $5 \mathrm{wt} \% \mathrm{NaCl}$ :

$$
\pi=2 *[(1000 \times 5) /(58.5 \times 95)] \times 0.082 \times(273+85)=43.97 \mathrm{~atm}
$$


The osmotic pressure difference between $\mathrm{DI}$ and $2 \mathrm{wt} \% \mathrm{NaCl}$ is $17.05 \mathrm{~atm}$.

$$
\Delta \pi=17.05-0=17.05 \mathrm{~atm}
$$

The osmotic pressure difference between $2 \mathrm{wt} \% \mathrm{NaCl}$ and $5 \mathrm{wt} \% \mathrm{NaCl}$ is 26.92 atm.

$$
\Delta \pi^{\prime}=43.97-17.05=26.92 \mathrm{~atm}
$$

The graph below shows the results calculated by OLI stream analyzer $2.0^{22.23}$, which is at the similar range of osmotic pressure compared with our rough calculation. In

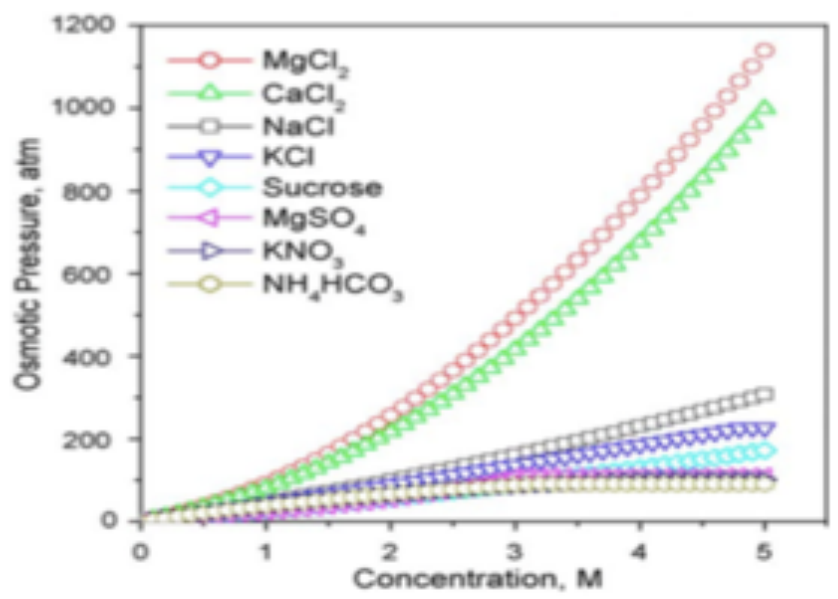

Figure 3-2: Osmotic pressure as a function of solution concentration at $25^{\circ} \mathrm{C}^{23}$.

The volume changes associated with the change in diameters of wet fibers were also calculated with the equation below:

$$
\text { Volume Change }=\left(R-r_{\text {initial }}\right)^{2} \pi h
$$

Here, $h$ is the length of fiber which is assumed to be constant, $R$ is the final poly(HIPE) fiber radius, and $r_{\text {initial }}$ is the initial radius of poly(HIPE) fiber. For HIPEs cured in $2 \mathrm{wt} \% \mathrm{NaCl}$, there is no $\mathrm{NaCl}$ concentration difference 
between inside and outside of the fiber since the curing bath contains same amount of $\mathrm{NaCl}$ as the HIPE's aqueous phase. No osmotic pressure effect is expected. $r_{\text {initial }}=R_{2} \mathrm{wt} \% \mathrm{NaCl}$.

However, when curing HIPEs in a bath containing pure DI water, expansion of the poly(HIPE) fibers are observed.

$$
V D I=\left(R-r_{\text {initial }}\right)^{2} \pi h=\left(\frac{676-525}{2}\right)^{2} \pi h=5.7 \times 10^{3} \pi h
$$

At the same time, shrinkage of poly(HIPE) fiber can be observed in fibers cured in bath containing $5 \mathrm{wt} \% \mathrm{NaCl}$.

$$
V 5 w t \% N a C l=\left(R-r_{\text {initial }}\right)^{2} \pi h=\left(\frac{415-525}{2}\right)^{2} \pi h=3.0 \times 10^{3} \pi h
$$

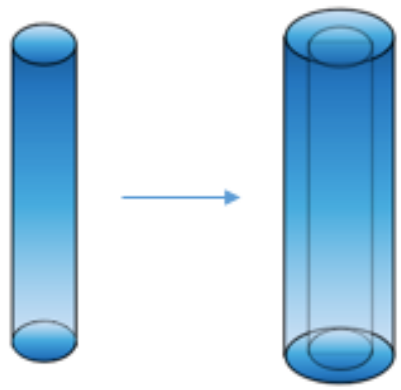

Figure 3-3: A schematic representation of poly(HIPE) fiber expansion.

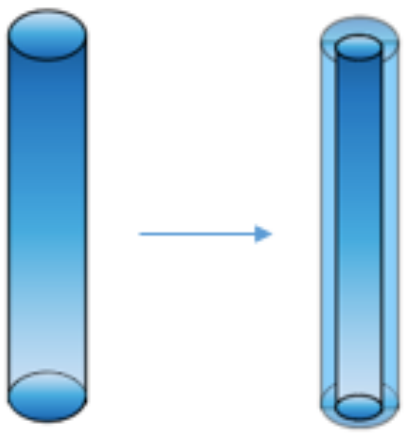

Figure 3-4: A schematic representation of poly(HIPE) fiber shrinkage. 
Data collected above indicated that HIPEs cured in DI water showed a large amount of volume expansion that was almost twice the magnitude of the shrinkage of HIPE cured in baths containing $5 \mathrm{wt} \% \mathrm{NaCl}$. At the same time, the osmotic pressure difference between $\mathrm{DI}$ and $2 \mathrm{w} \% \mathrm{NaCl}$ is smaller than the osmotic pressure difference between $2 \mathrm{wt} \% \mathrm{NaCl}$ and $5 \mathrm{wt} \% \mathrm{NaCl}$. Freezedried fibers were studied by scanning electron microscope. The diameter of dried fibers showed only a slight sensitivity to the different $\mathrm{NaCl}$ concentrations used in the bath. All samples had a diameter smaller than the inner diameter of the injection needle of $(0.838 \mathrm{~mm})$.

With regard to the discussion above, the wet samples were cured and stored in their curing liquid. Two variables: storage condition and curing bath condition are here considered separately in order to detect the main factors that cause osmotic pressure effect and how these two variables change poly(HIPE) fibers' properties. Additional experiments were conducted along these lines. Firstly, we analyze the effect of storage condition on the HIPES (before polymerization). Figure 3-5 shows the HIPE's structure after injectingon into $\mathrm{DI}$ water and $5 \mathrm{wt} \% \mathrm{NaCl}$ respectively at room temperature. The upper two pictures show the HIPEs' structure at the time just after injection, while the images below show the fiber structure change after storing in different baths for 24 hours. HIPE stored in DI water exhibited a large expansion due to the fact that $\mathrm{DI}$ water was driven into the fiber by the $\mathrm{NaCl}$ concentration gap. At the same time, a remarkable shrinkage was observed for 
HIPE stored in $5 \mathrm{wt} \% \mathrm{NaCl}$. It is clear that the osmotic pressure effect is significant.

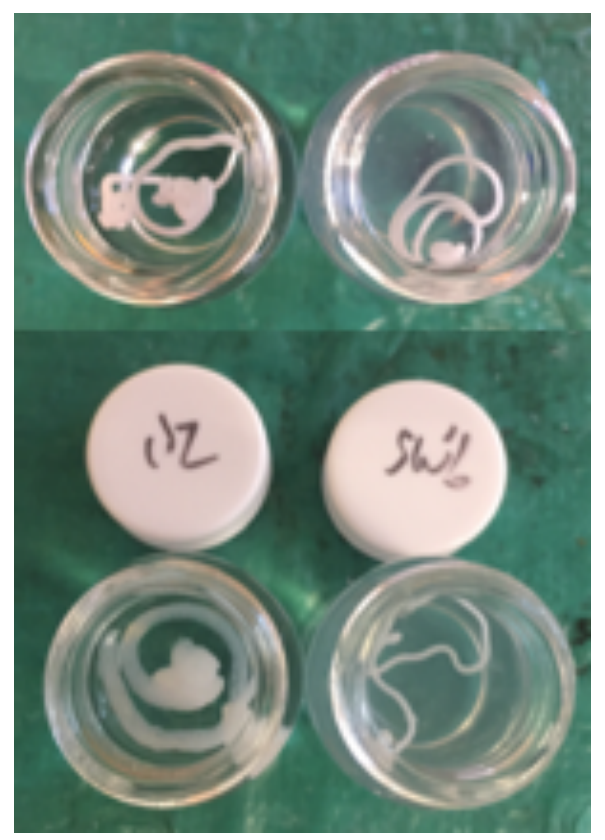

Figure 3-5: HIPE injected into different curing baths at room temperature (left) pure DI, (right) 5 wt\% $\mathrm{NaCl}$ solvent.;(above top) just after injection, (below bottom) $24 \mathrm{~h}$ later.

For further exploration of the separate effects of the storage condition and curing bath composition, samples cured under different curing bath conditions were washed by DI water for $24 \mathrm{~h}$, then immersed in $2 \mathrm{wt} \% \mathrm{NaCl}$ for 48h. By doing that, samples cured in different curing conditions are guaranteed to contain same amount of $\mathrm{NaCl}$ inside for further analysis of the effect of storage conditions. These fiber samples were then stored in either DI water, $2 \mathrm{wt} \% \mathrm{NaCl}$ solution or $5 \mathrm{wt} \% \mathrm{NaCl}$ solution for another $48 \mathrm{~h}$. Table 2 shows detailed data on the diameter of the resulting fibers. 
Table 2. Fiber Diameter (micron)

\begin{tabular}{|c|c|c|c|}
\hline $\begin{array}{c}\text { Curing Condition/ } \\
\text { Storage Condition }\end{array}$ & DI Water & $2 \mathrm{wt} \% \mathrm{NaCl}$ & $5 \mathrm{wt} \% \mathrm{NaCl}$ \\
\hline DI Water* & $641 \pm 143$ & $499 \pm 57$ & $460 \pm 62$ \\
\hline $2 \mathrm{wt} \% \mathrm{NaCl}^{*}$ & $519 \pm 67$ & $414 \pm 83$ & $380 \pm 21$ \\
\hline 5 wt\% NaCl* & $309 \pm 38$ & $324 \pm 26$ & $316 \pm 36$ \\
\hline
\end{tabular}

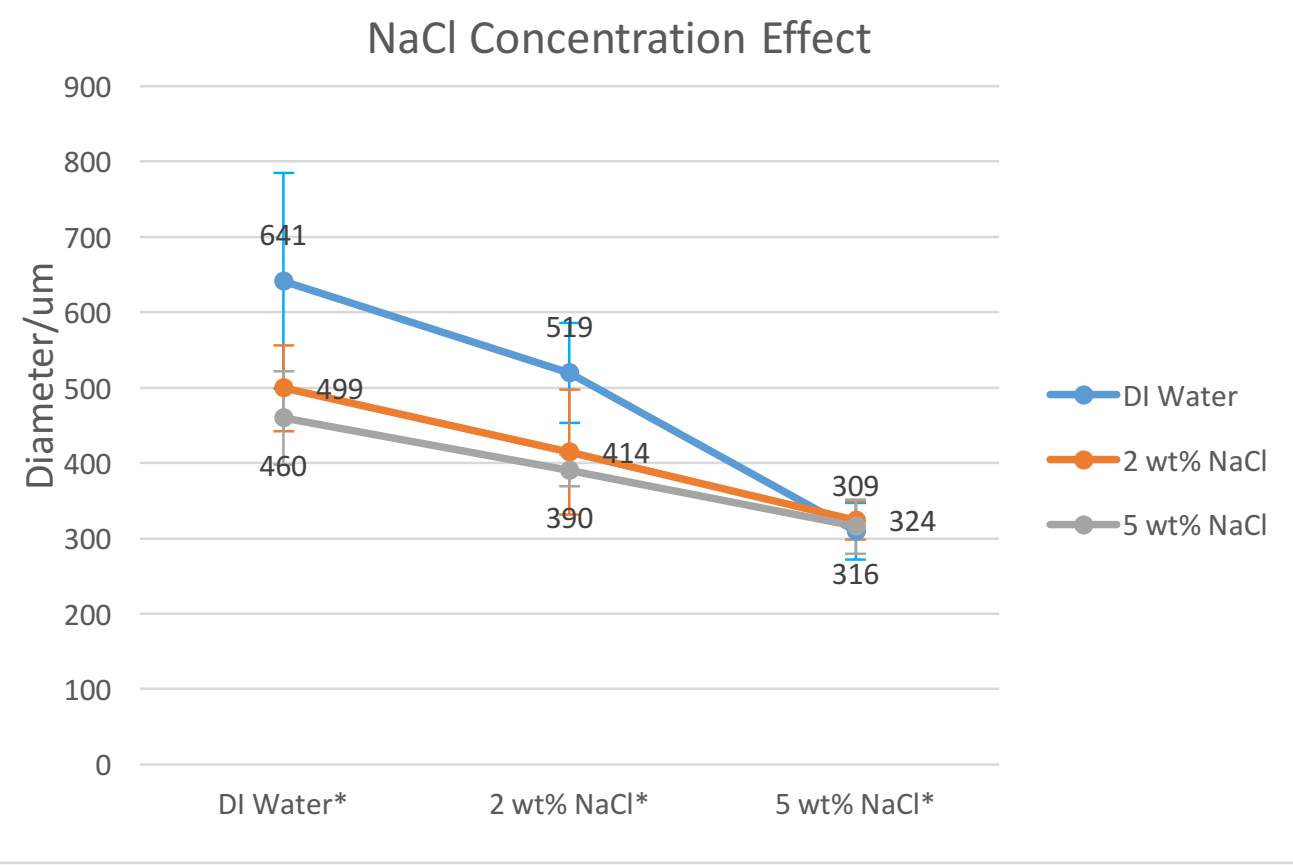

Figure 3-6: Wet poly(HIPE) fiber diameter changes under the effect of electrolyte concentration in the curing bath and the storage bath. 
Figure 3-6 indicates that storage conditions have a significant effect on the fiber diameter especially for samples cured in DI water. The blue line corresponds to samples cured in DI water and stored in DI water bath, 2 wt\% $\mathrm{NaCl}$ bath and $5 \mathrm{wt} \% \mathrm{NaCl}$ bath respectively. At the same time, the orange line shows samples cured in a $2 \mathrm{wt} \% \mathrm{NaCl}$ curing bath and the gray line present samples cured in a $5 \mathrm{wt} \% \mathrm{NaCl}$ curing bath. As the data above shows, for poly(HIPE) fibers cured in same curing bath condition but stored in different storage conditions, fiber diameter decrease with the increase of $\mathrm{NaCl}$ concentration in the storage bath, and fibers cured in DI water showed the most sensitivity to storage bath condition. Subsequent examination revealed that curing conditions also affect the fiber structure.

A detailed discussions of sample cured in DI water is provided below. During the curing process, polymerization happens takes place from the interior of HIPEs since there is no initiator in the curing bath. At the same time, osmotic pressure drive water flow into the HIPE and increases its water-to-oil ratio in the surface region. As more DI water flows into the HIPE, aqueous droplets become larger, and break up of oil phase can also be expected as a result of the swelling of water droplets. 


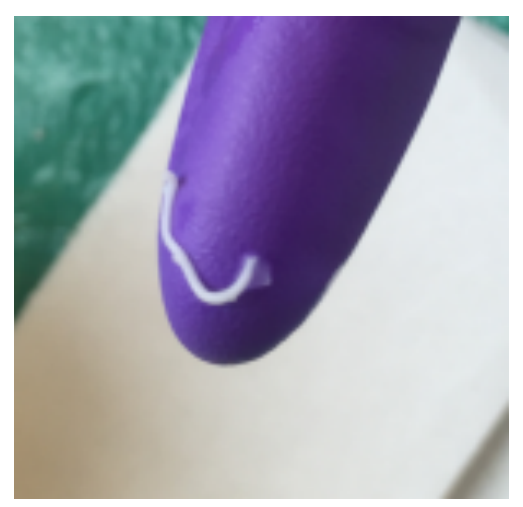

Figure 3-7: Poly(HIPE) fiber cured in DI water.

At the same time, the depleted NaPS concentration in the surface region results in lower polymerization rates and longer polymerization times. Since polymerization starts from the center of fiber, longer polymerization time can also cause the loss of some monomers into the curing bath. The solubility of $2-\mathrm{EHA}$ is $0.1 \mathrm{~g} / \mathrm{I}$ at $25^{\circ} \mathrm{C}$ and that of EGDMA is $1 \mathrm{~g} / \mathrm{l}$ at $20^{\circ} \mathrm{C}$. After curing, the fiber density is lower, which means it has lower mechanical strength. This can explain the remarkable effect of storage conditions on fiber cured in DI water. It also explains why HIPEs cured in DI water gain large amount of volume expansion compared with the shrinkage volume of HIPE cured in curing bath containing $5 \mathrm{wt} \% \mathrm{NaCl}$. Osmotic pressure not only takes effect while poly(HIPE) fibers were completely cured, but also plays a role before polymerization takes place. This effect changes the water-to-oil ratio in the HIPE and provides structures with large aqueous phase volume. 


\section{3-2-2: Effect of Initiator}

Acting as initiator, NaPS triggers polymerization of oil phase inside HIPEs. When adding NaPS into the curing bath, the overall initiator content in the curing system is increased, and the resulting changes in overall polymerization rate will affect the poly(HIPE) fibers' structures.

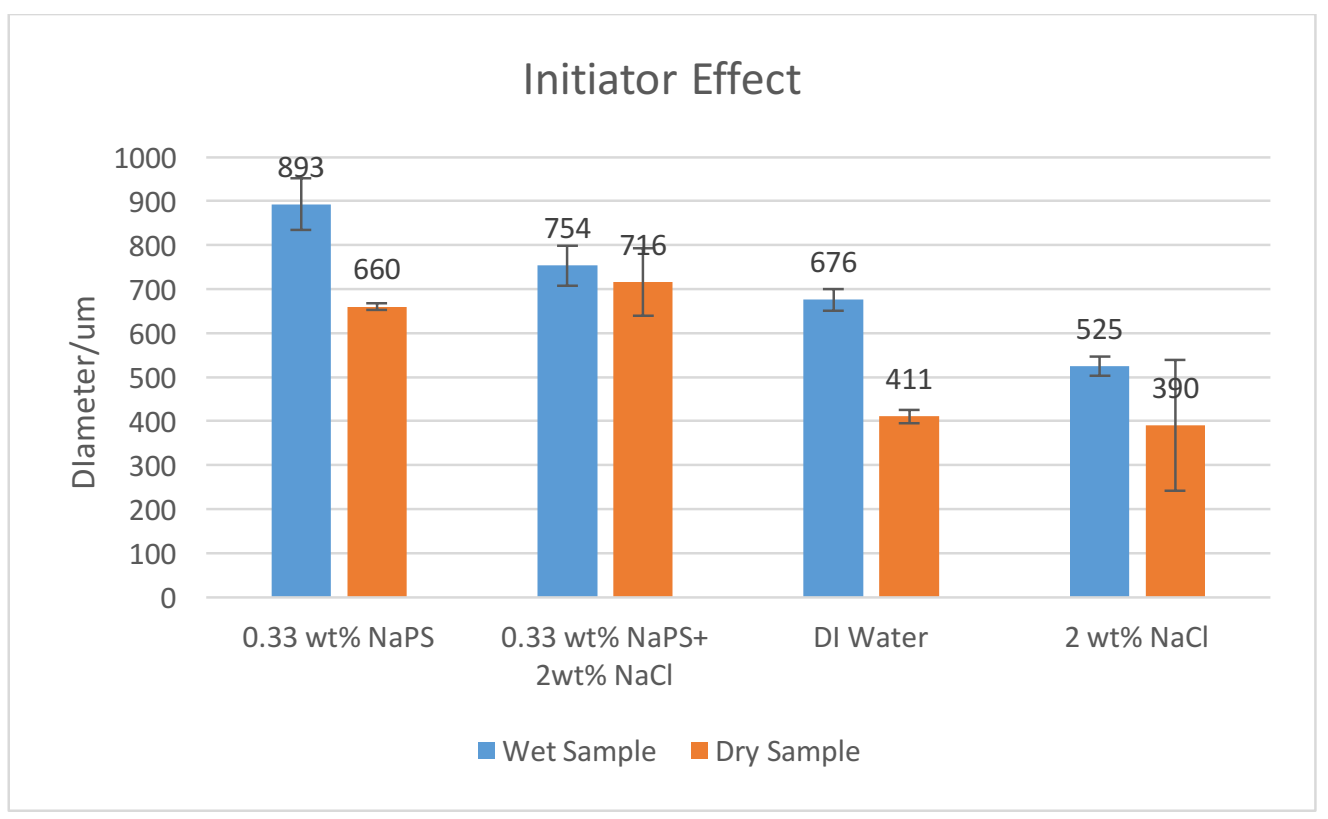
curing bath.

Figure 3-8: Poly(HIPE) fiber diameter changes under the effect of initiator concentration in the

Figure 3-8 provides the diameter of the poly(HIPE) fibers cured in baths containing different amount of initiator. Compared to fibers cured in baths without initiator, the poly(HIPE) fiber gain larger diameters when NaPS is present in the curing bath. Polymerization kinetics can be used to explain this phenomenon. During curing, polymerization and water transport occur simultaneously once HIPE is injected into the curing bath. Initiator added in 
curing bath increases the reaction rate on the fiber surface since this region is exposed to initiator both within and outside the fiber. Under this situation, polymerization can first occur on the surface of the fiber which helps to freeze the fiber structure. With the help of this initial polymer barrier at the surface, the diffusion effect may be retarded, and less polymer loss into the curing bath is expected. Overall, more polymerization occurs in this kind of curing bath, and this results in thicker poly(HIPE) fibers. Meanwhile, with the addition of more initiator in the curing system, higher polymerization rate contributes to less curing time being required, which leads, in-turn, to less monomer diffusion and loss into the bath. We tried curing HIPEs in baths with NaPS only as well as in a curing bath containing $\mathrm{NaCl}$ and $\mathrm{NaPS}$. The latter curing bath condition simulates the aqueous phase of HIPEs. As Figure 3-8 indicates, no significant distinction in diameters was observed for fibers cured under these two conditions. The osmotic effect is also observed by comparing fibers cured in 0.33 wt\% NaPS which swelled to a larger diameter than HIPEs cured in a bath containing $0.33 \mathrm{wt} \% \mathrm{NaPS}$ and $2 \mathrm{wt} \% \mathrm{NaCl}$. This is due to the fact that water in curing bath will flow into the HIPE which contains a higher concentration of $\mathrm{NaCl}$ than the bath.

The samples as described above revealed fibers with diameters larger than the needle inner diameter $(0.838 \mathrm{~mm})$ both for fibers cured in baths containing 0.33 wt\% NaPS or 0.33 wt\% NaPS plus 2 wt\% $\mathrm{NaCl}$. Die swelling is regarded as the explanation for this phenomenon. 
Die swelling usually occurs in polymers with high molecular weight.

When entering a die, the increase of shear stress leads to stretched polymer molecules. Once the polymer is released from the high-stress condition inside the die, the molecule will regain its own shape, which results in the stream diameter increasing and exceeding that of the die's diameter. When samples were cured in a bath containing initiator, polymerization of the surface region helps to freeze the die-swollen structure. 


\section{3-2-3: Effect of PGS}

PGS serves as a surfactant stabilizing the aqueous phase droplets within the oil phase in our water-in-oil emulsion system, due to its functional groups which attract to monomers and other portions of the molecules which are attractive to water. Mixing various amount of PGS into the curing bath helps to elucidate what role PGS plays in curing the system. Two series of curing bath conditions are under study: PGS mixed in DI water and PGS mixed in $2 \mathrm{wt} \% \mathrm{NaCl}$.

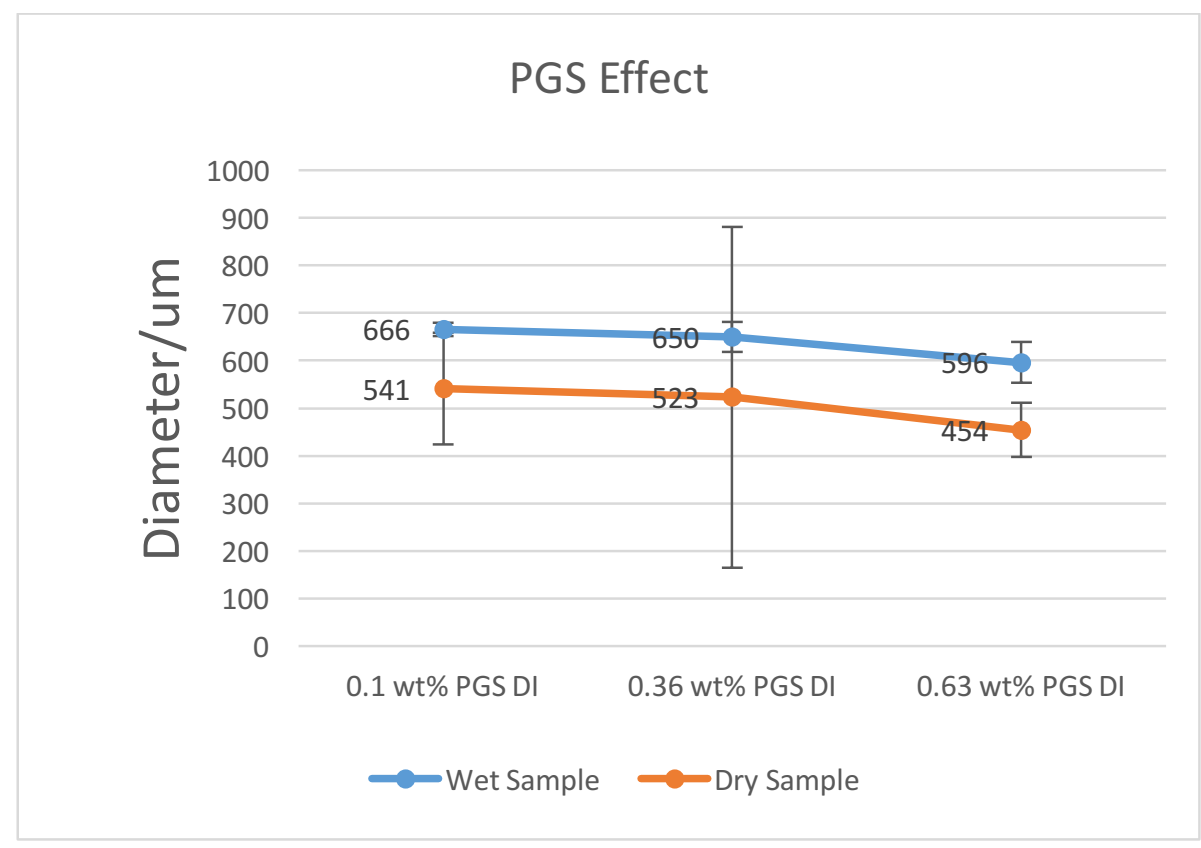

Figure 3-9: Poly(HIPE) fiber diameter change under the effect of surfactant concentration in the curing bath. 


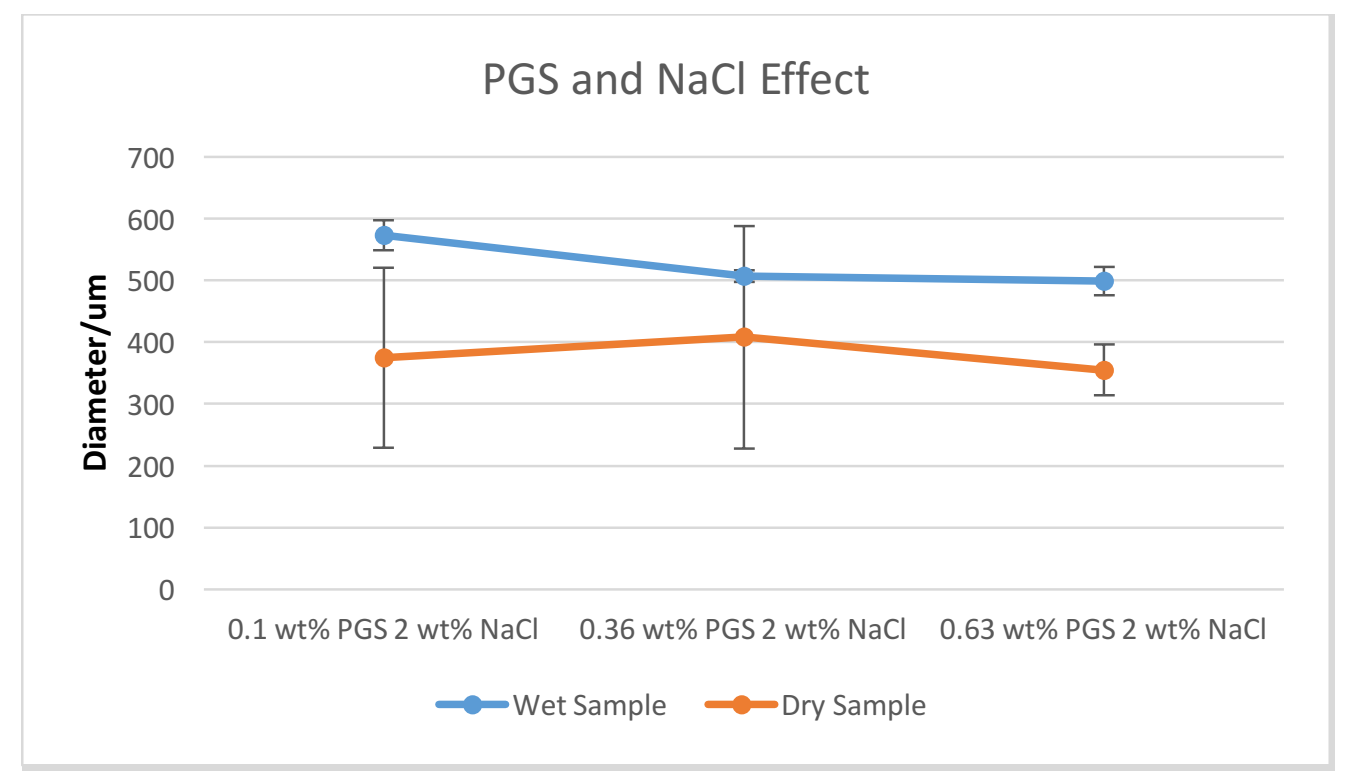

Figure 3-10: Poly(HIPE) fiber diameter change under the effect of surfactant and electrolyte concentrations in the curing bath.

Figure 3-9 and Figure 3-10 show that with the increase of PGS added into the curing bath, fiber diameters only decreased slightly. This suggests PGS applied in the curing bath has no significant impact on changing fiber diameter both for wet samples and freeze dried samples. At the same time, remarkably large error bars are observed especially for samples cured in curing bath containing both PGS and $2 \mathrm{wt} \% \mathrm{NaCl}$ due to the fact that PGS has poor solubility in $2 \mathrm{wt} \% \mathrm{NaCl}$ solvent as the Figure 3-11 below suggests. 


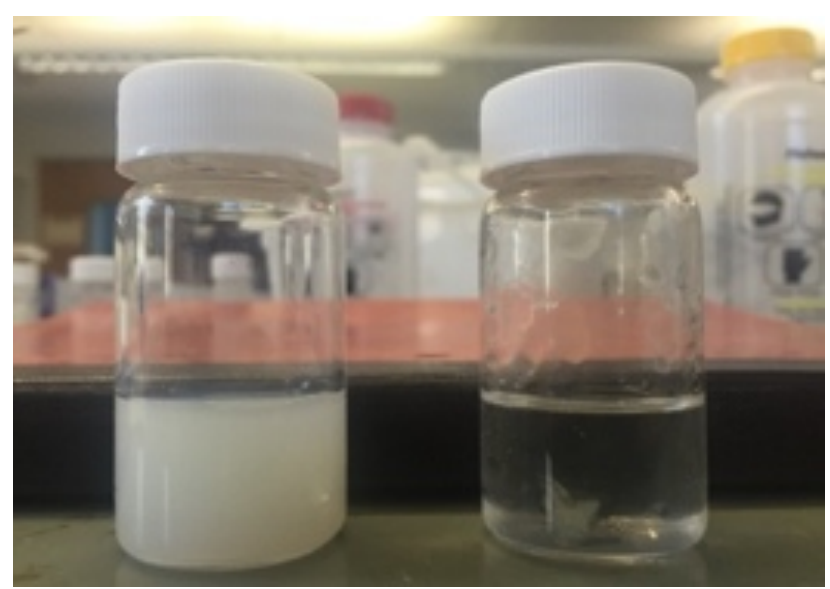

Figure 3-11: (left) PGS in DI water, (right) PGS in $2 \mathrm{wt} \% \mathrm{NaCl}$.

The presence of dissolved inorganic salts is not conducive to formation of hydrogen bonds between the water and surfactant. The beaker on the left contains PGS dissolved in DI water which is a uniformly milky colored fluid while in the beaker in right contains PGS dissolved in $2 \mathrm{wt} \% \mathrm{NaCl}$, in which PGS assembles at the bottom and on the side wall. When HIPEs is surrounded with large amount of PGS, some molecules in the oil phase can be dragged into the water by its hydrophobic portions. Formation of less polymer in the fiber is expected in this case because of the loss of oil phase. 


\section{3-3: Discussion}

The poly(HIPE) fiber diameter analysis provides straightforward and easily tested structural information. In different curing bath conditions, the diameter values differ due to physical or chemical reactions. Adding $\mathrm{NaCl}$ to the curing bath generates an electrolyte concentration gap, and osmotic pressure drives aqueous flow into or out of the poly(HIPE) fibers causing expansion or shrinkage. Adding initiator, $\mathrm{NaPS}$, into the curing bath helps forming poly(HIPE) fibers with larger diameter. The increased fiber diameter can be the result of the reduction of polymer lost to the bath. As for the surfactant PGS, its presence in the curing bath has little impact on the fiber diameter. 


\section{Chapter 4: Effect of Curing Bath Conditions on the Morphology of Poly(HIPE) Fibers}

\section{4-1: Morphology Study of Poly(HIPE)s Fiber Surface}

\section{4-1-1: Effect of $\mathrm{NaCl}$}

How osmotic pressure drives aqueous flow into or out of the fiber was

discussed in Chapter 3, section 3-2-1, and the variation of fiber diameter in different curing bath conditions was also explained. In this section, the surface morphology of the poly(HIPE) fibers as examined by SEM is discussed. The osmotic pressure impact on the poly(HIPE) fiber surface is further analyzed.

In order to study the effect of the electrolyte $\mathrm{NaCl}$ on surface morphology, the curing bath conditions were chosen to be deionized water, curing baths containing $2 \mathrm{wt} \% \mathrm{NaCl}$ or $5 \mathrm{wt} \% \mathrm{NaCl}$, and the curing temperature was set at $85^{\circ} \mathrm{C}$. Figure $4-1$ exhibits that the poly(HIPE) fiber surface reveals different open cell sizes when cured in the three different curing baths. Among those three samples, fibers cured in a bath with $2 \mathrm{wt} \% \mathrm{NaCl}$ generates the most uniform surface with less open cells, meanwhile fibers cured in a bath with $5 \mathrm{wt} \% \mathrm{NaCl}$ generates smaller open cells as compared with sample cured in DI water. Three factors: osmotic pressure, coalescence and Ostwald ripening are the main reasons causing these morphology differences. 

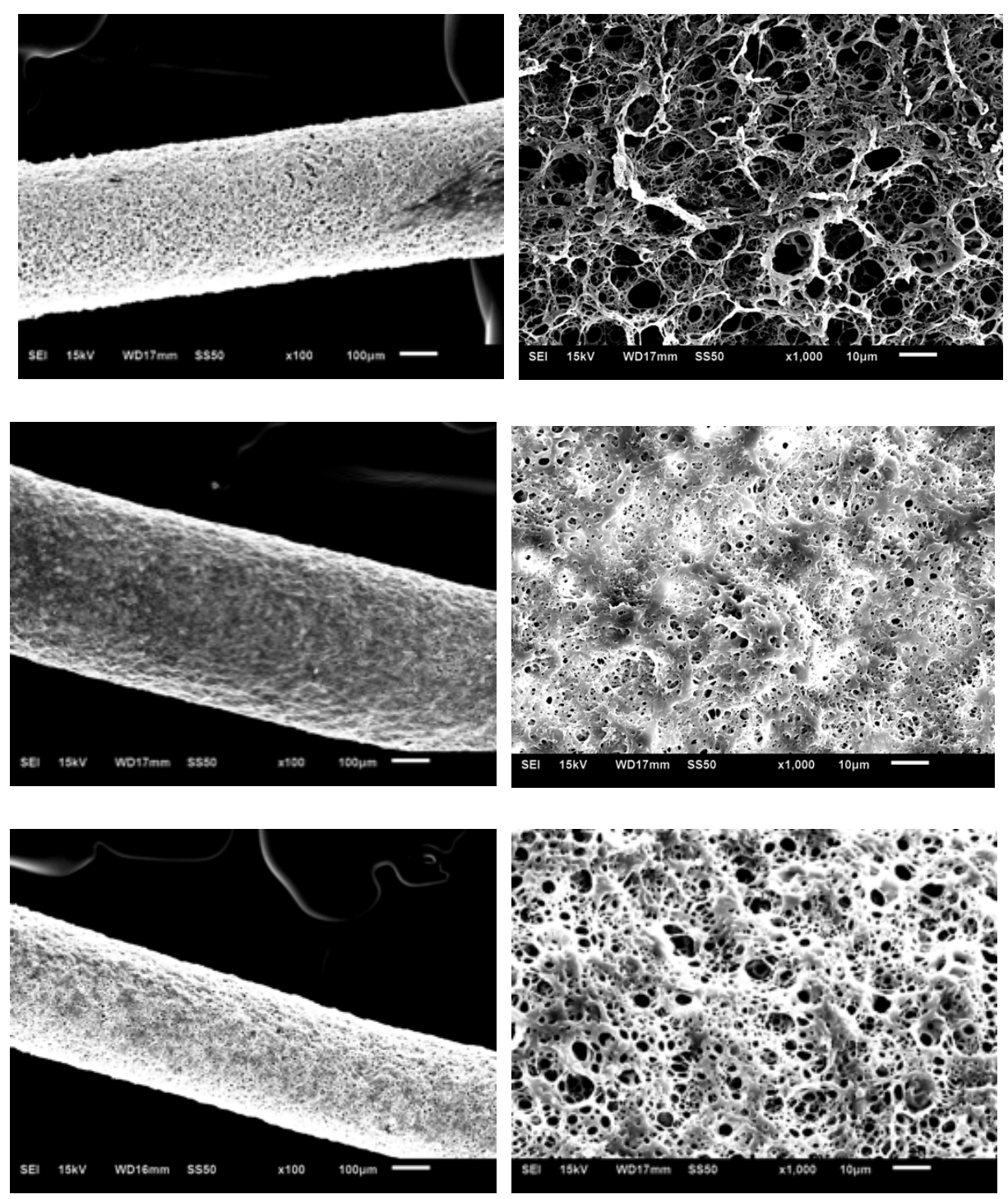

Figure 4-1: Surfaces of pol(HIPE)fibers prepared in different curing baths at $85^{\circ} \mathrm{C}$. Top is DI water; middle is $2 \mathrm{wt} \% \mathrm{NaCl}$; bottom is $5 \mathrm{wt} \% \mathrm{NaCl}$. (Left) fiber surface image, scale bar in 100um (right) high magnification image, scale bar in $10 u m$. 
Since HIPEs are thermodynamic unstable systems with high internal surface area, they tend to reduce their total free energy and lower the interfacial area basically by coalescence and Ostwald ripening. Figure 4-2 provides detailed information of emulsions system.

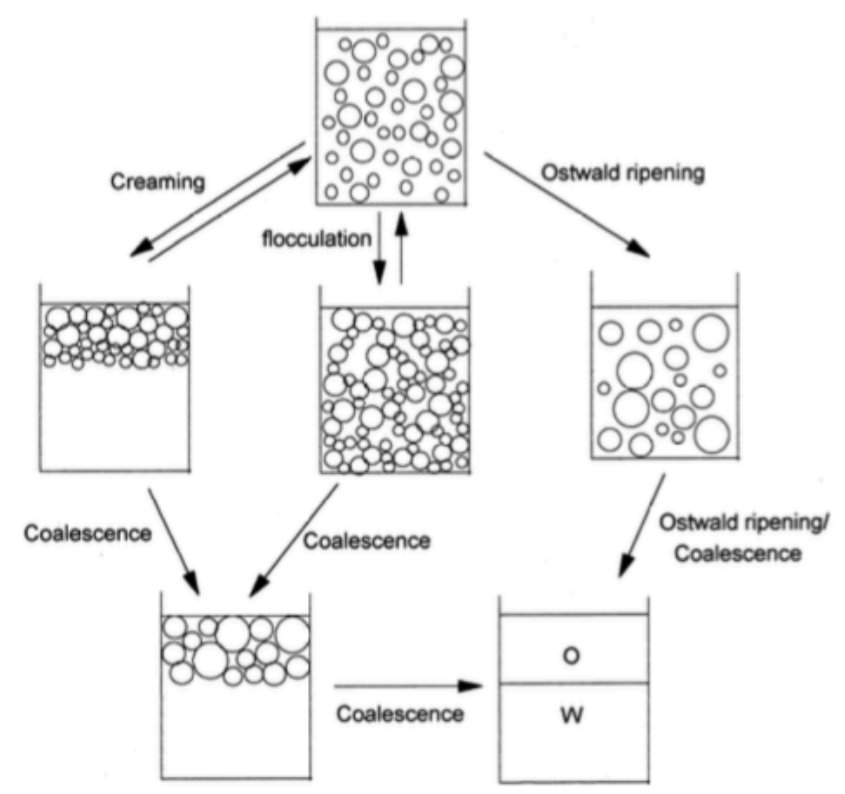

Figure 4-2: Emulsion breakdown process ${ }^{24}$.

Coalescence is accompanied by film drainage and rupture ${ }^{24}$ : when two nearby droplets contact and combine into one droplet as a result of forces that break up the thin film between them, coalescence occurs. Ostwald ripening is another phenomenon referring to large droplets in the emulsion growing while shrinkage of nearby smaller droplets occurs. Both mechanisms lead to the formation of larger droplets, which are then expected to yield a larger open cells after curing. However, unlike coalescence, Ostwald ripening does 
not require the two affected droplets to be closely positioned. The driving force is the transport of dissolved material through dispersion medium ${ }^{25}$, and a bigger droplets and a relatively smaller one will be generated after transport occurs. Previous research has shown that electrolyte can be of great help to prohibit emulsion break up by retarding coalescence and Ostwald ripening ${ }^{26}$, which partially explains the large open cells observed on the surface for fibers cured in DI water.

When curing the fibers in pure DI water, water in the curing bath flows into the aqueous phase of the HIPE immediately due to the osmotic pressure impact. Coalescence also enlarges droplets in the emulsion resulting in large void size after polymerization. Swelling of the fiber is observed at the surface region of poly(HIPE) fiber as Figure 4-3 suggests. Since polymerization started from the inside of the fiber and proceeds to the surface, the diluted initiator concentration in the surface region (as discussed in chapter 3 ) decreases the polymerization rate, and some of the monomer in the HIPE will also be dissolved into the bath. In this case, less polymerization and more openness in the surface region is expected. 


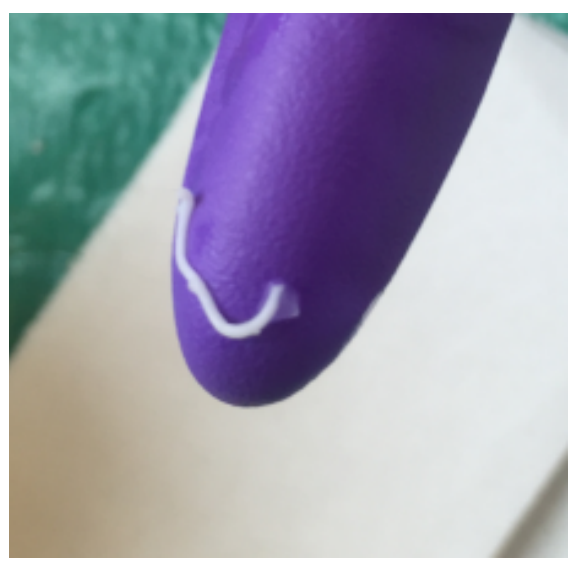

Figure 4-3: Swelling of the poly(HIPE) fiber.

For samples cured in a bath containing $2 \mathrm{wt} \% \mathrm{NaCl}$, the HIPEs will not be affected by osmotic pressure effects, AWK Adding electrolyte into the curing baths also inhibits the PGS in the HIPE from migrating into the curing bath according to observation in section 3-2-3, which shows that PGS has lower solubility in $\mathrm{NaCl}$ solution. This helps to enhance the stability of HIPEs system since PGS remains inside the HIPE.

As for the sample cured in curing bath containing $5 \mathrm{wt} \% \mathrm{NaCl}$, osmotic pressure drives water from inside the HIPE to flow out, which generates some additional openings in the fiber surface. This explains why there are more open cells in this sample compared with the fiber cured in $2 \mathrm{wt} \% \mathrm{NaCl}$. 


\section{4-1-2: Effect of NaPS}

Initiator added to the curing bath enables the polymerization of the

HIPE to occur quickly at its surface. Comparison of the fiber surface

morphologies in Figure 4-4 indicates that NaPS added into the curing bath

helps to form small open cells on the fiber surface.
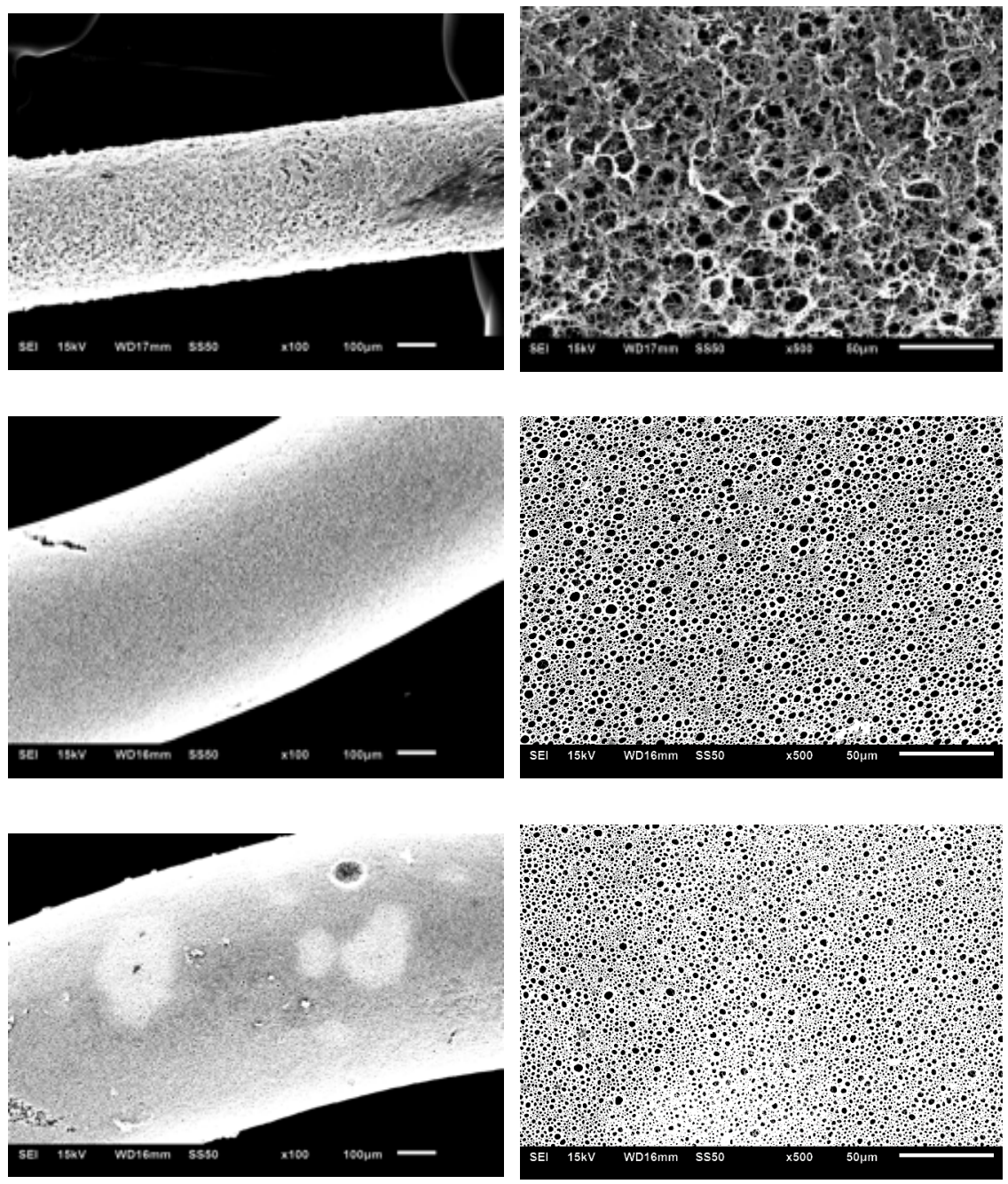

Figure 4-4: The surfaces of fibers prepared in different curing baths at $85^{\circ} \mathrm{C}$. Top two are DI water; middle 0.33 wt \% NaPS; bottom, $0.33 \mathrm{wt} \% \mathrm{NaPS}$ and $2 \mathrm{wt} \% \mathrm{NaCl}$. Left, fiber surface image; right high magnification image. 
Uniform and smooth surfaces were observed both using curing baths containing NaPS with or without the electrolyte $\mathrm{NaCl}$. Consideration of the polymerization kinetics can be used to explain this phenomenon. Compared with fibers cured in deionized water or in a bath containing $2 \mathrm{wt} \% \mathrm{NaCl}$, polymerization happens first within the surface of fiber when it is cured in a bath containing initiator. The well organized surface morphology gives evidence to he fact that the first polymerized surface region will be hardly affected by factors such as coalescence, Ostwald ripening and water transport to or from the HIPE. However, in curing baths containing only 0.33 wt\% NaPS, the osmotic pressure effect caused by electrolyte differences is revealed in the form of open cells on the poly(HIPE) fiber surface that are larger compared with fibers cured with 0.33 wt\% NaPS and 2 wt\% $\mathrm{NaCl}$.

In the competition between polymerization rate and diffusion, initiator added to the curing bath enables faster polymerization and a smoother fiber surface. 


\section{4-1-3: Effect of PGS}

In section 3-2-3, it was shown that increasing the surfactant PGS concentration in the curing bath reveals no remarkable effects on the fiber's diameter. At the same time, PGS will uniformly disperse within deionized water but not within $2 \mathrm{wt} \% \mathrm{NaCl}$ solvent. In this section we discuss how this phenomenon affects the poly(HIPE) fiber surface.

As Figure 4-5 suggests, with an increasing concentration of PGS in the curing bath, larger open cell on the surface are obtained. Since PGS added to curing bath disturbs the oil-water balance within the HIPE, part of the oil phase can be solubilized into the curing bath and this results in less polymerization at the surface and thus a more porous surface structure. 

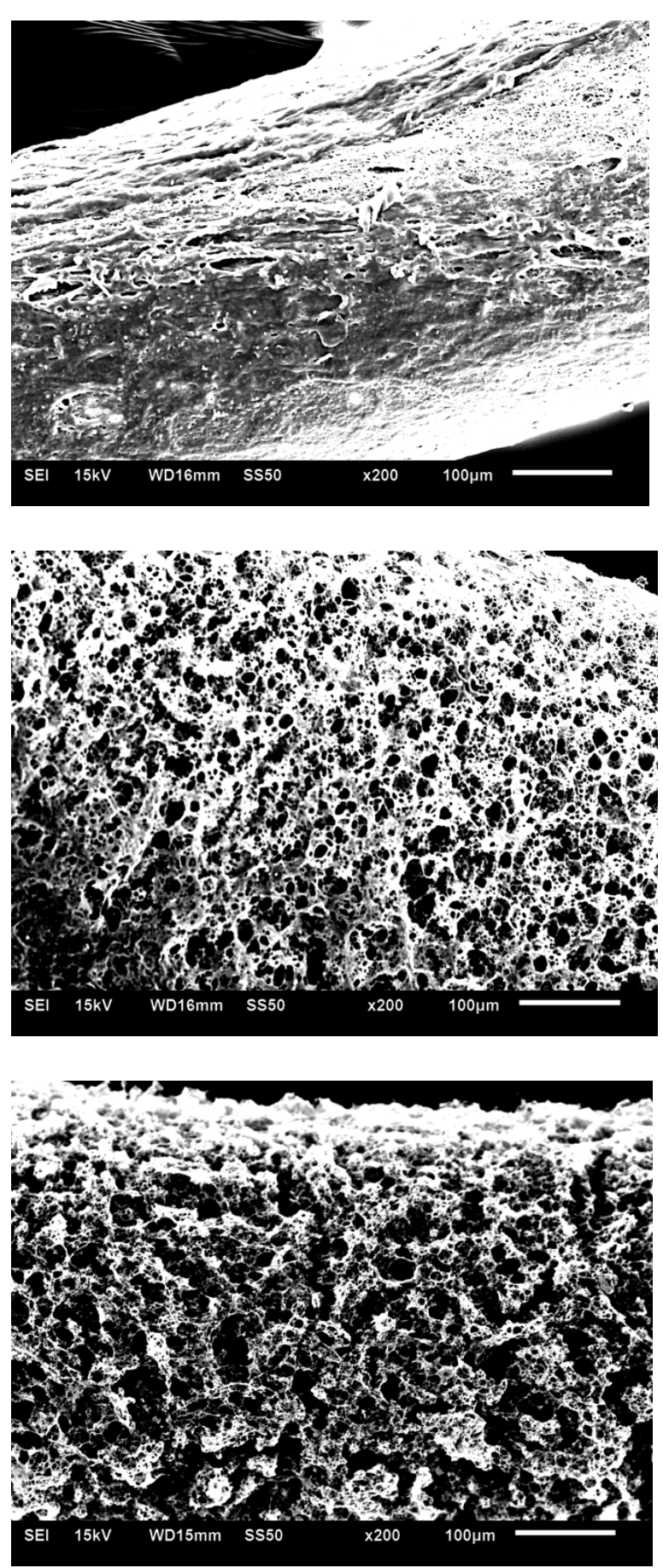

Figure 4-5: The surfaces of fibers prepared in different curing baths at $85^{\circ} \mathrm{C}$. Top is $0.1 \mathrm{wt} \% \mathrm{PGS}$; middle is $0.36 w t \%$ PGS; bottom is $0.63 w t \%$ PGS. 
For curing baths containing PGS and $2 \mathrm{wt} \% \mathrm{NaCl}$, Figure 4-6 suggests that the surface structure differs even in the same fibers due to the nonuniform PGS distribution in the salt solution in the bath. When emulsions are in contact with a region containing a large amount of PGS, part of oil phase can be solubilized into the water by the PGS causing large openness in surface after polymerization. On the other hand, when emulsions encounter a region with no surfactant on it, surface morphology will be more like samples cured in $2 \mathrm{wt} \% \mathrm{NaCl}$ which generates only a small degree of openness.

Thus, the presence of PGS in the curing bath will cause instability of the HIPE during the curing process, which can result in a loss of oil phase available for polymerization. 

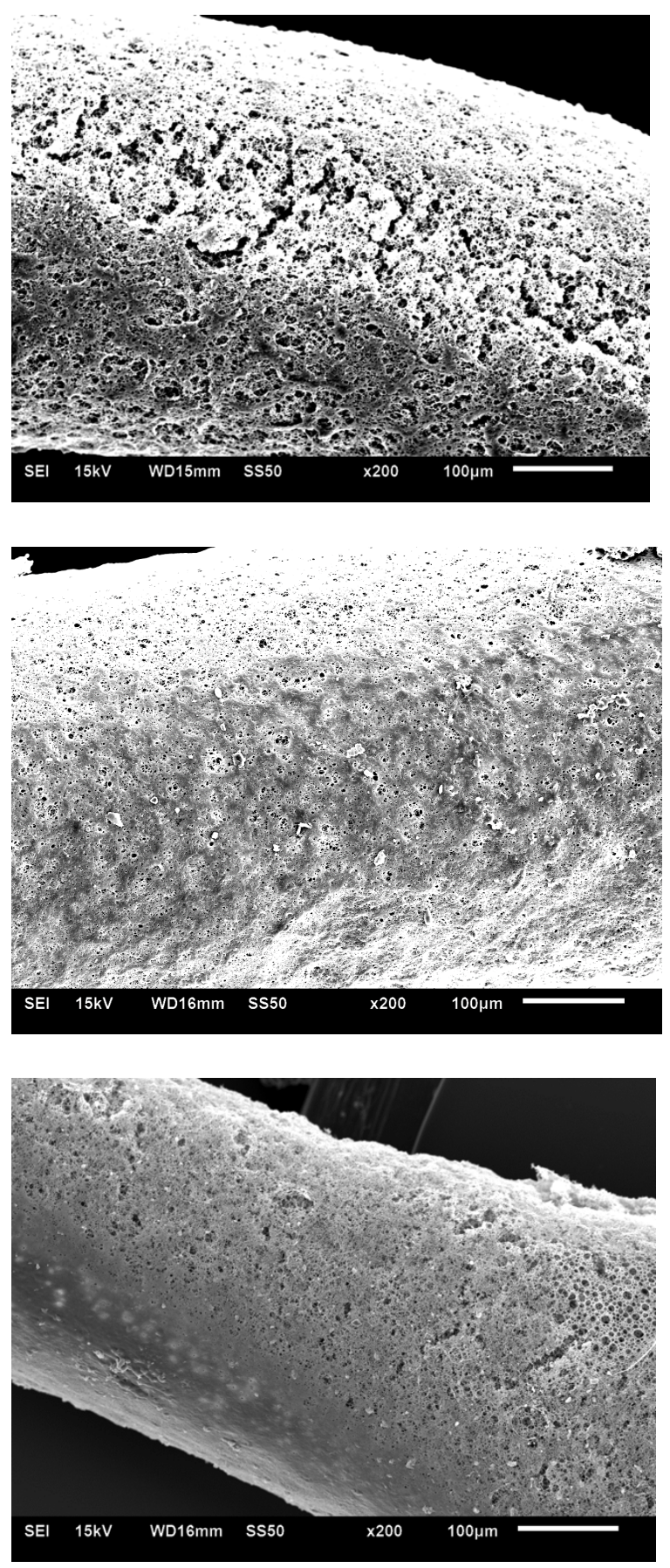

Figure 4-6: The surfaces of poly(HIPE) fibers prepared in different curing baths at $85^{\circ} \mathrm{C}$. Top is 0.1 wt $\%$ $P G S$ and $2 \mathrm{wt} \% \mathrm{NaC}$, middle is $0.36 \mathrm{wt} \% \mathrm{PGS}$ and $2 \mathrm{wt} \% \mathrm{NaCl}$, bottom is $0.63 \mathrm{wt} \% \mathrm{PGS}$ and $2 \mathrm{wt} \%$ $\mathrm{NaCl}$. 


\section{4-1-4: Effect of Temperature}

Previous polymerization reaction kinetics research ${ }^{19}$ indicated that our HIPE formula can be fast cured at $85^{\circ} \mathrm{C}$, but a higher temperature contributes to an even faster polymerization. In this section, experiments in which fibers are cured in baths at $85^{\circ} \mathrm{C}$ or $95^{\circ} \mathrm{C}$ are used to explore temperature effects on enhanced polymerization rate and the resulting changes of the poly(HIPE) fiber surface morphology. Curing bath conditions are listed below in Table 3.

\section{Table 3. Curing Bath Comditions}

\begin{tabular}{|c|c|}
\hline \multirow{4}{*}{$\mathrm{NaCl}$ Concentration } & DI Water \\
\cline { 2 - 2 } & $2 \mathrm{wt} \% \mathrm{NaCl}$ \\
\cline { 2 - 2 } & $5 \mathrm{wt} \% \mathrm{NaCl}$ \\
\hline \multirow{2}{*}{ Initiator } & $0.33 \mathrm{wt} \% \mathrm{NaPS}$ \\
\cline { 2 - 2 } & $0.33 \mathrm{wt} \% \mathrm{NaPS}, 2 \mathrm{wt} \% \mathrm{NaCl}$ \\
\hline
\end{tabular}

For HIPEs cured in baths with different $\mathrm{NaCl}$ concentration, no remarkable open cell size differences on the fiber surface were found when the bath temperature was raised from $85^{\circ} \mathrm{C}$ to $95^{\circ} \mathrm{C}$. However, a smoother surface and denser polymer were observed upon curing at the higher temperature. 
a.

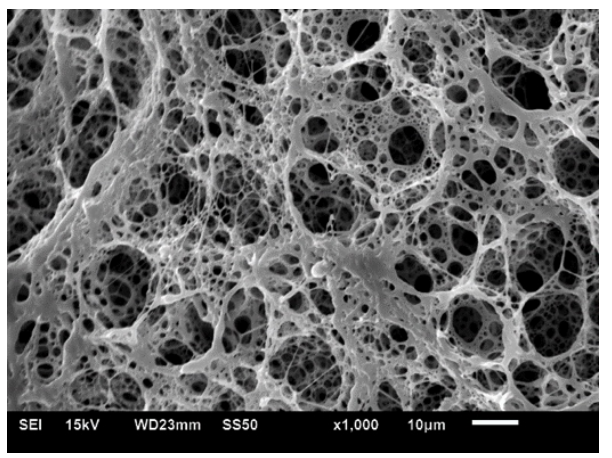

b.
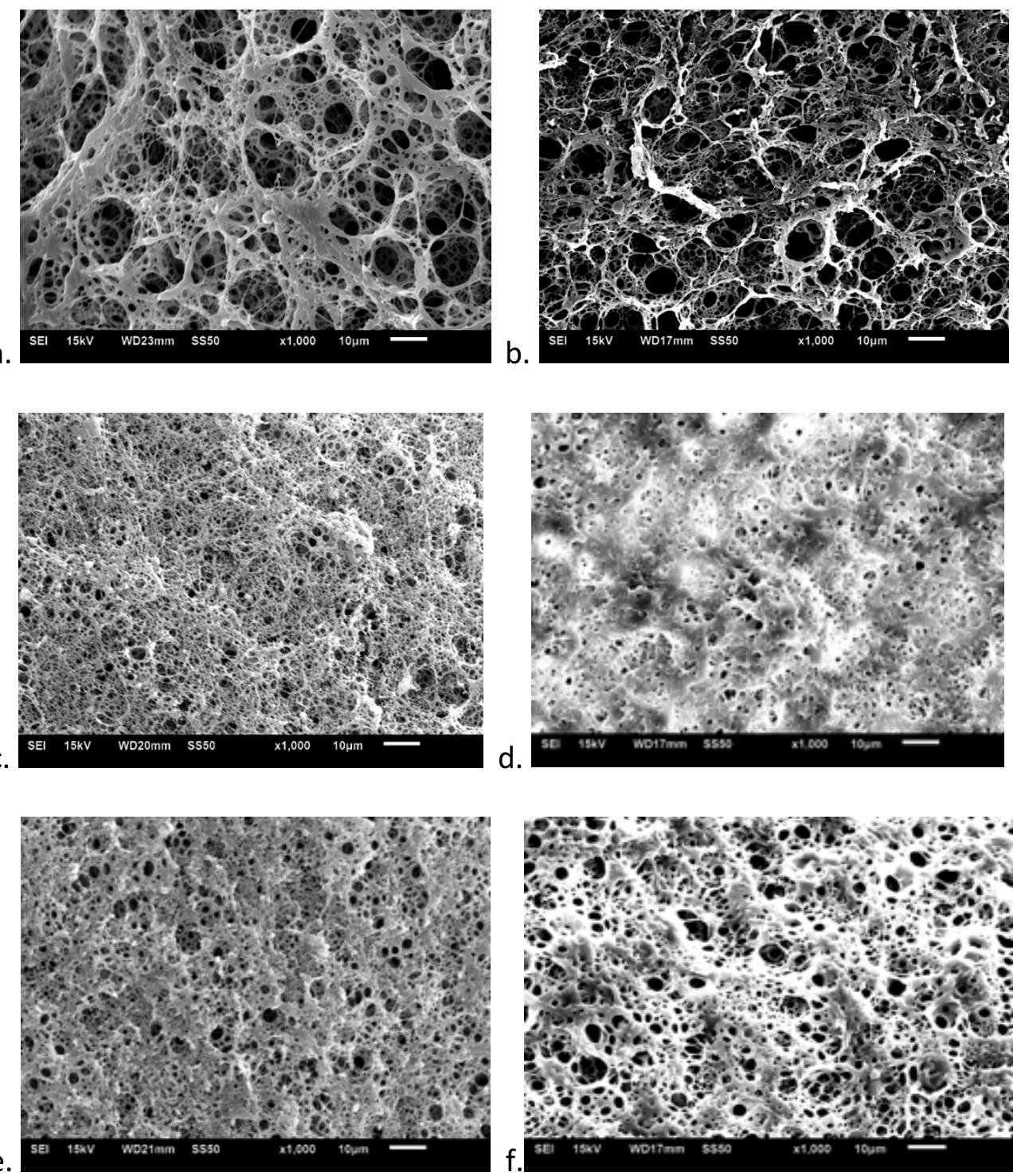

Figure 4-7: SEM image of poly(HIPE) fiber surface prepared in different curing baths: a. $95^{\circ} \mathrm{C}$ DI water; b. $85^{\circ} \mathrm{C} \mathrm{DI}$ water; c. $95^{\circ} \mathrm{C} 2 \mathrm{wt} \% \mathrm{NaCl} ; d .85^{\circ} \mathrm{C} 2 \mathrm{wt} \% \mathrm{NaCl}$; e. $95^{\circ} \mathrm{C} 5 \mathrm{wt} \% \mathrm{NaCl} ; f .85^{\circ} \mathrm{C} 5 \mathrm{wt} \% \mathrm{NaCl}$. 
For HIPEs cured in baths containing initiator (Figure 4-8), raising the temperature reduces the size of open cells on the fiber surface significantly. At $95{ }^{\circ} \mathrm{C} 0.33$ wt\% NaPS curing bath condition, we observe the most uniform surface with only a few small open cells among all of the curing conditions tested.

a.
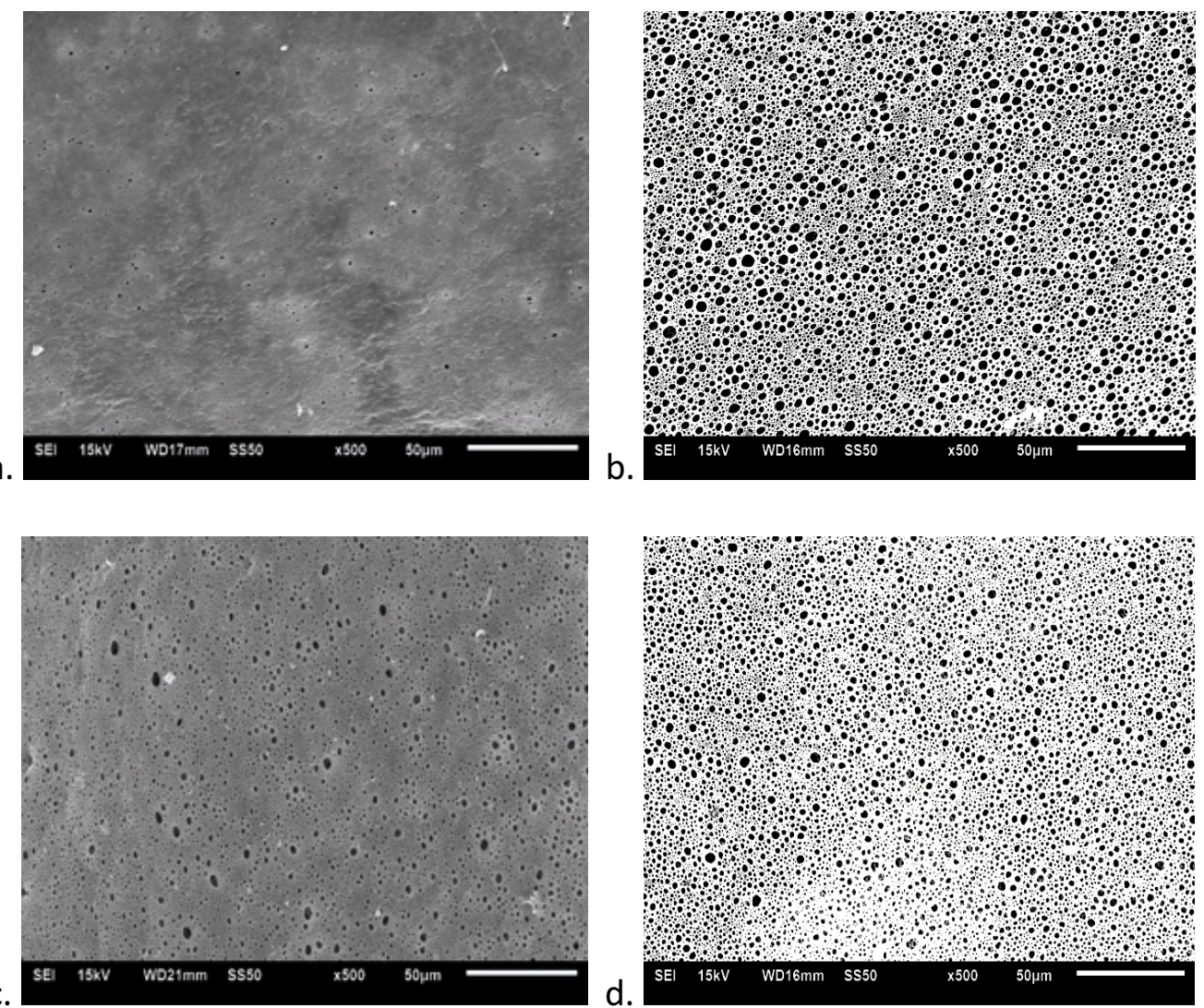

Figure 4-8: SEM image of poly(HIPE) fiber surface prepared in different curing baths. a. $95^{\circ} \mathrm{C} 0.33 w t^{\circ}$ $\mathrm{NaPS} ; b .85^{\circ} \mathrm{C} 0.33 w t \% \mathrm{NaPS} ; c .95^{\circ} \mathrm{C} 0.33 w t \% \mathrm{NaPS}$ and $2 \mathrm{wt} \% \mathrm{NaCl} ; d .85^{\circ} \mathrm{C} 0.33 w t \% \mathrm{NaPS}$ and $2 w t \% \mathrm{NaCl}$.

In the competition between polymerization kinetic and the diffusion process, raising the temperature helps enhance polymerization rates and 
shortens the time required to finish the HIPE polymerization. At the same time, diffusion of monomers happens once we inject HIPEs into the curing bath which can result in loss of HIPE and a more open poly(HIPE) fiber structure. When polymerization kinetics dominates, a smoother surface morphology is obtained. 


\section{4-1-5: Closed-cell Surface Fiber}

For further exploration, a closed-cell surface poly(HIPE) fiber was

obtained by adding 0.66 wt $\%$ NaPS to a $85^{\circ} \mathrm{C}$ curing bath. As Figure 4-9

indicates, only a few open cells which are nanometer scale in diameter are

observed on the poly(HIPE) fiber surface.

a.

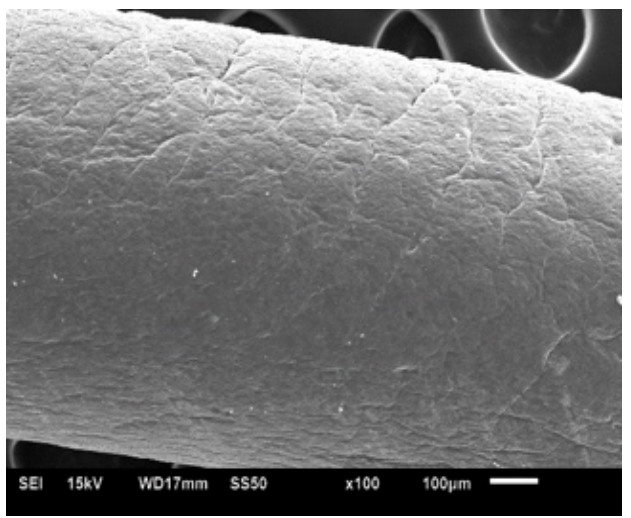

C.

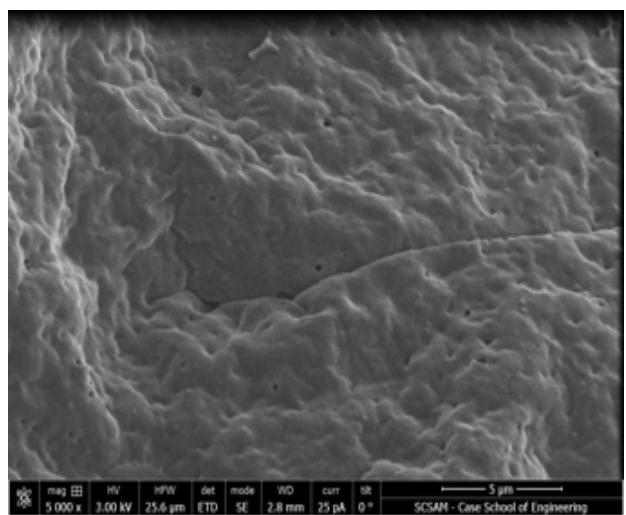

b.
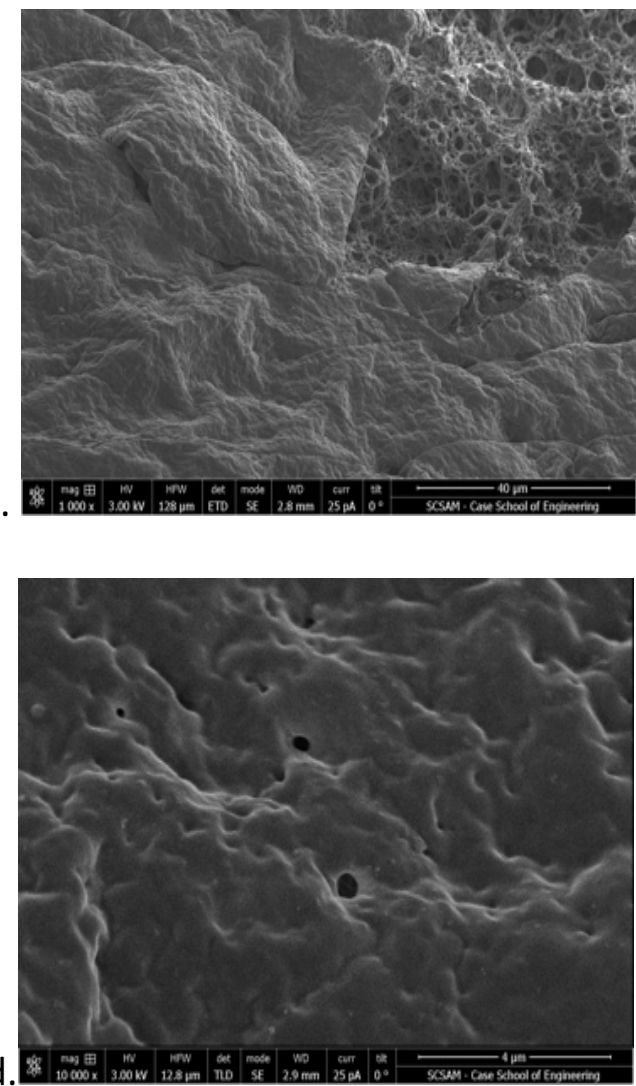

Figure 4-9: Poly(HIPE) fibers, curing bath 0.66wt\% NaPS $85^{\circ} \mathrm{C}$. a. poly(HIPE) fiber surface morphology $b$. High magnification image (both fiber surface and inside structure) $c$, $d$. High magnification surface image with openness. 
According to the previous results, enhancing the polymerization rate by increasing the NaPS concentration in the curing bath is a worthwhile approach to achieve fibers with smaller open cells on the surface. With a large amount of initiator added in the system, the polymerization rate of the interface between HIPEs and curing bath is high enough to overcome the diffusion due to osmotic pressure, which enables the generation of closed-cell surface. Shear stress is another important factor contributing to the formation of closed-cell surface fiber. Since HIPEs are high water-to-oil ratio emulsions, voids should occur on the poly(HIPE) fiber surface. During injection through the needle, the oil phase can relocate and occupy the places where droplets used to be located. Quick polymerization helps to freeze the structure immediately. Analysis of shear stress will be provided later in this chapter.

When increasing the curing temperature from $85^{\circ} \mathrm{C}$ to $95^{\circ} \mathrm{C}$, we obtain poly(HIPE) fibers with only a little openness on the surface (Figure 4-10), proving that with large amount of initiator added in curing system, increasing the curing temperature still have significant effect on enhancing the polymerization rate and producing a smoother morphology. We can generate closed-cell surface poly(HIPE) fibers by changing the curing bath components and the curing temperature. 

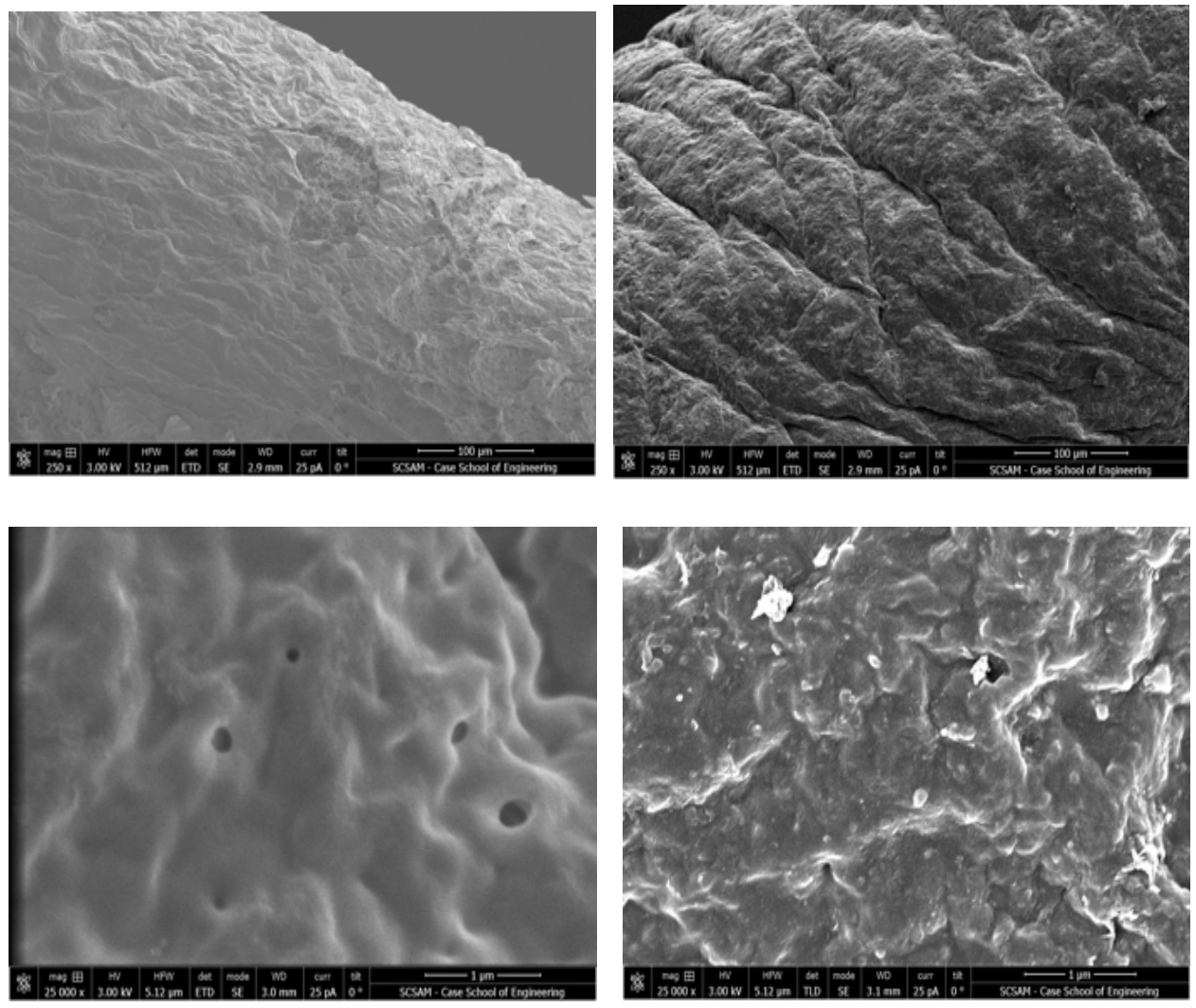

Figure 4-10: Poly(HIPE) fibers, curing bath $0.66 w t \%$ NaPS. (left) $85^{\circ} \mathrm{C}$, poly(HIPE) fiber surface morphology and high magnification image surface image with openness in below. (right) $95^{\circ} \mathrm{C}$, poly(HIPE) fiber surface morphology and high magnification image surface image.

Poly(HIPE) fiber samples shown above in Figure 4-10 are prepared by washing for $24 \mathrm{~h}$ in DI water followed by a $24 \mathrm{~h}$ isopropanol washing. Monomer and attached surfactant can be removed by this process. Tetrahydrofuran (THF), an intensive polymer solvent, can be used as an alternative solvent to replace isopropanol for further exploration. Figure 4-11 shows sample cured in a bath containing 0.66 wt\% NaPS and washed for $24 \mathrm{~h}$ with DI water and then 
by THF for $24 \mathrm{~h}$. No open cells can be observed when the curing bath temperature is chosen to be $95^{\circ} \mathrm{C}$, which indicates the fiber that we fabricated can be defined as closed-cell surface fiber down to a very small scale.
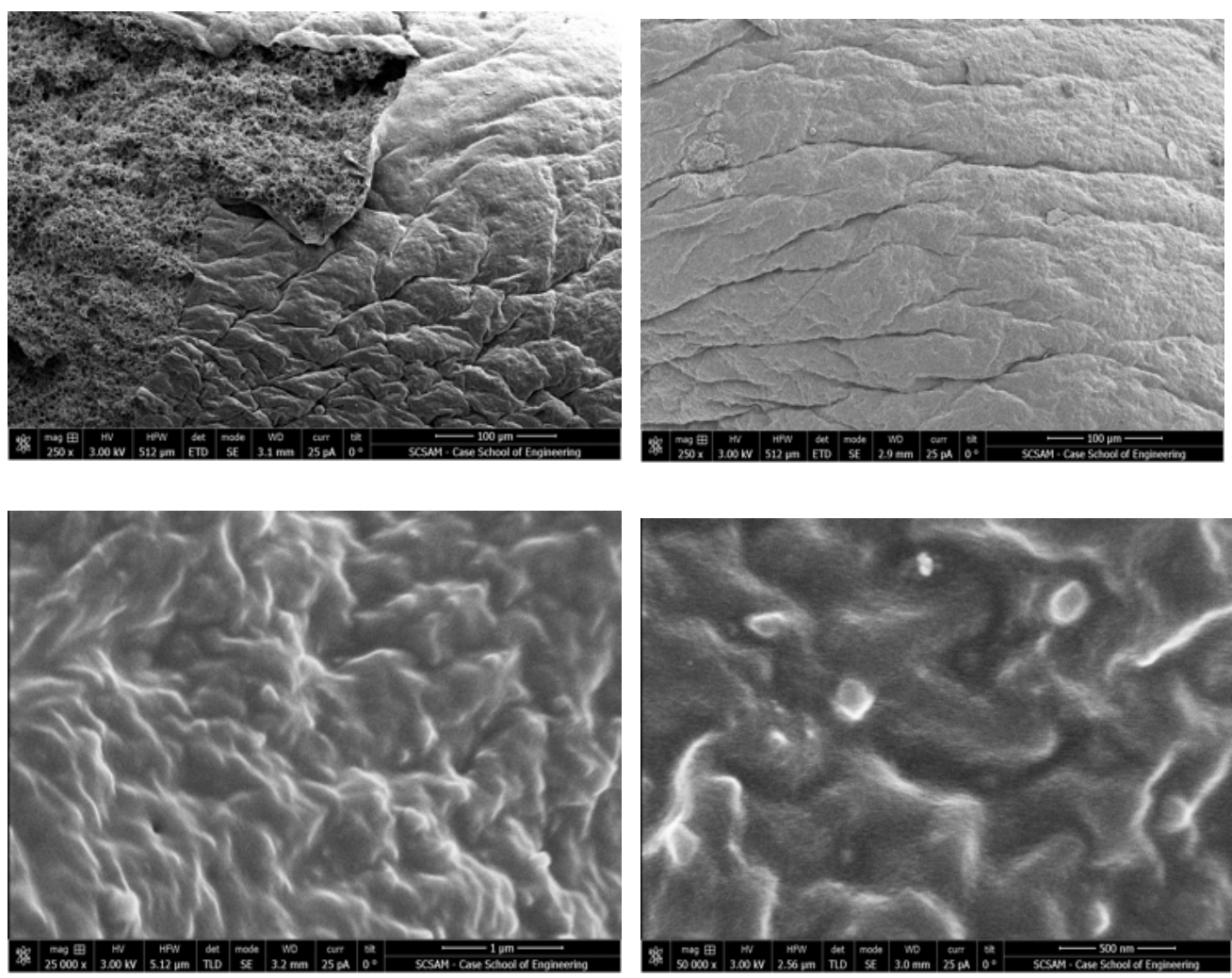

Figure 4-11: Poly(HIPE) fibers, curing bath 0.66wt\% NaPS, washed by DI water for $24 \mathrm{~h}$ then THF for $24 \mathrm{~h}$. (Left) $85^{\circ} \mathrm{C}$ poly(HIPE) fiber surface morphology and high magnification image surface image with openness in below. (Right) $95^{\circ} \mathrm{C}$ poly(HIPE) fiber surface morphology. 


\section{4-2: Morphology Study of Poly(HIPE) Fibers Cross-section}

\section{4-2-1: Shear Stress Effect}

When injecting HIPEs through needle, the solid metal surrounding the flow generates a shear stress on HIPEs boundary. Assuming the HIPE to be a Newtonian fluid, the shear stress is proportional to velocity gradient.

$$
\tau=-\mu \frac{d u}{d y}
$$

where $\mu$ is the dynamic viscosity of the fluid; $u$ is the flow velocity along the boundary; $y$ is the height above the boundary ${ }^{27,28}$. According to this formula,

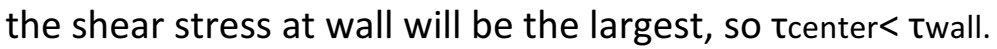

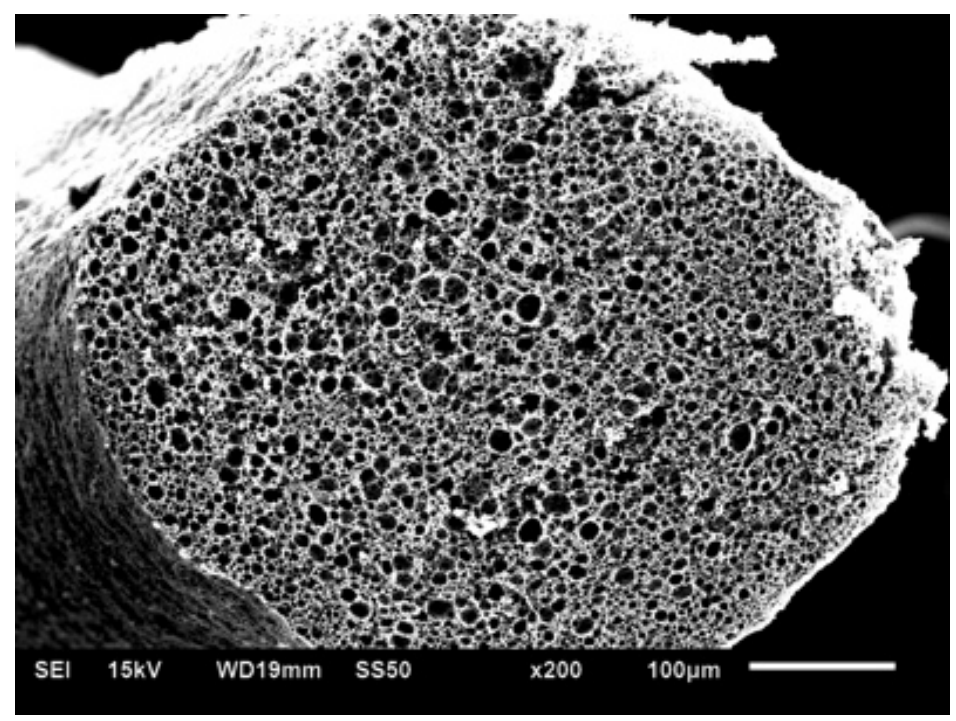

Figure 4-11: Poly(HIPE) fiber cross-section. 
Figure 4-12 is the poly(HIPE) fiber cross section area, which shows the distribution of cell sizes inside the fiber is not uniform. In the center the large cell diameter can reach approximately 20 um, however at the surface cell size is about 5um. When injecting emulsions through the needle, droplets near the wall will receive higher shear stress as compared to the droplets in the middle of the stream, which will lead to the formation of smaller spherical droplets in that region. 


\section{4-2-2: "Skin Layer" Analysis}

Adding $\mathrm{NaCl}$ to the curing batch leads to thicker surface skin layer as

Figure 4-13 indicated. Structures of poly(HIPE) fiber cured in curing bath with or without $\mathrm{NaCl}$ are studied. For samples cured in a bath with $2 \mathrm{wt} \% \mathrm{NaCl}$ or 5 $w t \% \mathrm{NaCl}$, an increased boundary thickness contributes to the formation of an obvious surface skin layer. This can be the result of surfactant diffusing from the interior of the fiber into the bath-HIPE interface, which becomes physically entrapped and thus cannot be washed away by isopropanol. A skin layer was typically found in poly(HIPE) fibers cured in a bath containing electrolyte.

a.
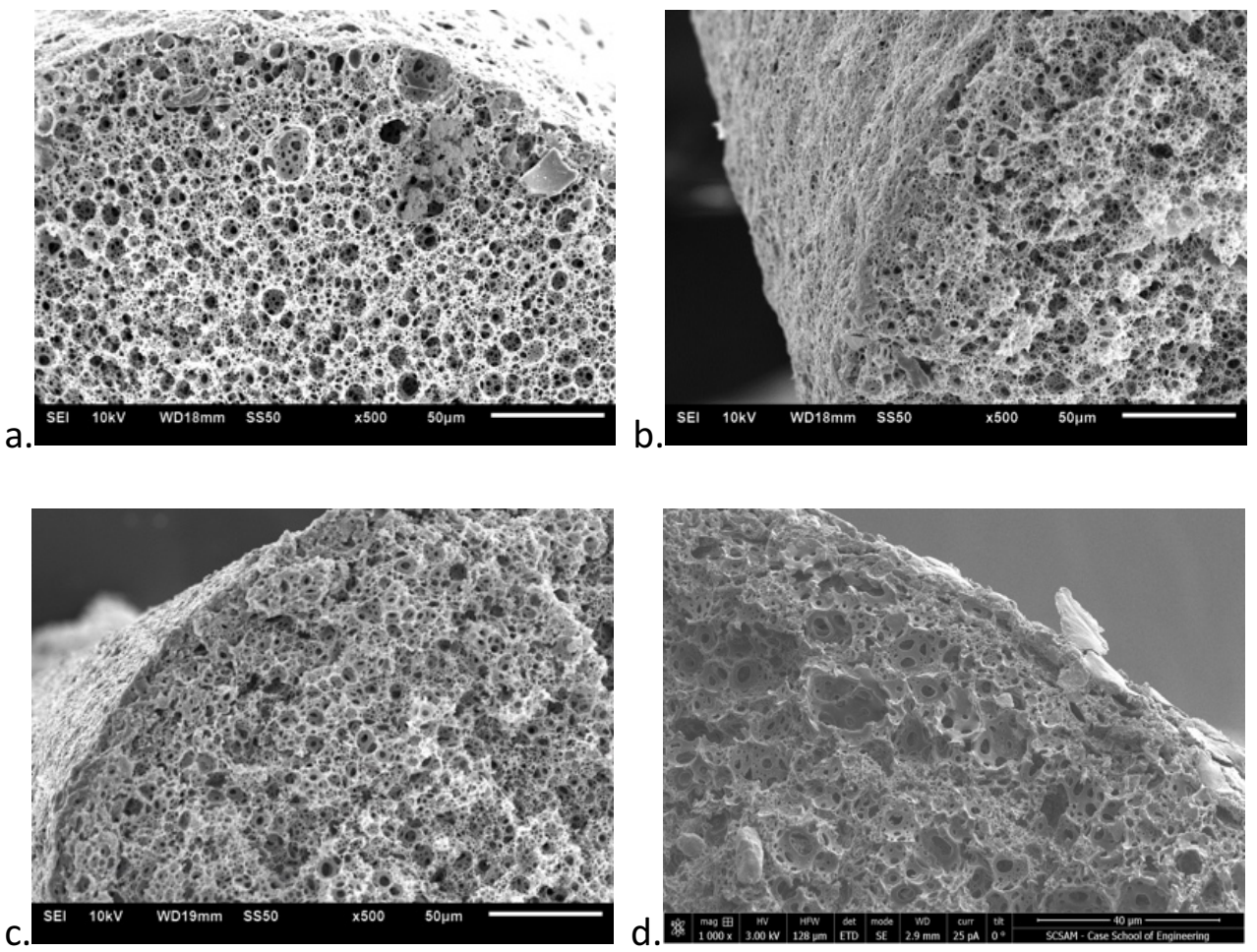

Figure 4-12: Poly(HIPE) fiber cross section a. Cured in DI Water at $85^{\circ} \mathrm{C}, \mathrm{b}$. Cured in $2 \mathrm{wt} \% \mathrm{NaCl}$ at $85^{\circ} \mathrm{C}, \mathrm{c}$. Cured in $5 \mathrm{wt} \% \mathrm{NaCl}$ at $85^{\circ} \mathrm{C}$. High magnification image of fiber cured in $5 \mathrm{wt} \% \mathrm{NaCl}$ at $85^{\circ} \mathrm{C}$. 


\section{4-3: Discussion}

The poly(HIPE) fiber structure and morphology can be adjusted by changing the components in the curing bath. Osmotic pressure caused by electrolyte $\mathrm{NaCl}$ concentration gap drives water flow into or out of the fiber and this enlarges the openness of the poly(HIPE) fiber surface. To adjust the poly(HIPE) fiber surface openness, high temperature and the presence of initiator in curing bath contributes to increased polymerization rate and helps to form small open cells at the fiber surface. On the other hand, PGS added in curing bath disturbs the water-to-oil balance in the HIPE, and a large openness in the fiber surface is observed. The chart below provides a summary of the poly(HIPE) fiber surface open cell sizes. By varying the components added in the curing bath we can obtain fibers with surface open cell ranging from 0 to 30 micron (where the poly(HIPE) fiber diameter is about several hundred microns). This process has the potential to control and design poly(HIPE) fiber surface open cell size for specific applications. 
Table 4. Poly(HIPE) Fibers Surface Openness

\begin{tabular}{|c|c|}
\hline Curing Bath Condition & $\begin{array}{c}\text { Surface Open Cell } \\
\text { Diameter/um }\end{array}$ \\
\hline DI Water $85^{\circ} \mathrm{C}$ & 13 \\
\hline $2 \mathrm{wt} \% \mathrm{NaCl} 85^{\circ} \mathrm{C}$ & 3 \\
\hline 5 wt $\% \mathrm{NaCl} 85^{\circ} \mathrm{C}$ & 4 \\
\hline 0.33 wt $\% \mathrm{NaPS} 85^{\circ} \mathrm{C}$ & 3 \\
\hline 0.33 wt $\% \mathrm{NaPS} 2 \mathrm{wt} \% \mathrm{NaCl} 85^{\circ} \mathrm{C}$ & 2.5 \\
\hline 0.1 wt\% PGS DI $85^{\circ} \mathrm{C}$ & 1 \\
\hline 0.36 wt\% PGS DI $85^{\circ} \mathrm{C}$ & 19 \\
\hline 0.63 wt\% PGS DI $85^{\circ} \mathrm{C}$ & 30 \\
\hline DI Water $95^{\circ} \mathrm{C}$ & 13 \\
\hline $2 \mathrm{wt} \% \mathrm{NaCl} 95^{\circ} \mathrm{C}$ & 3 \\
\hline $5 \mathrm{wt} \% \mathrm{NaCl} 95^{\circ} \mathrm{C}$ & 4 \\
\hline 0.33 wt $\% \mathrm{NaPS} 95^{\circ} \mathrm{C}$ & 0.8 \\
\hline 0.33 wt\% NaPS 2 wt\% $\mathrm{NaCl} 95^{\circ} \mathrm{C}$ & 1 \\
\hline 0.66 wt $\% \mathrm{NaPS} 85^{\circ} \mathrm{C}$ & 0.3 \\
\hline 0.66 wt $\% \mathrm{NaPS} 95^{\circ} \mathrm{C}$ & 0.1 \\
\hline
\end{tabular}




\section{Chapter 5: Conclusions and Future Works}

\section{5-1: Conclusions}

From the discussions above, fabricating porous fibers with poly(HIPE) as the starting material has been proven to be an effective approach. An understanding of how components introduced to the curing bath influence poly(HIPE) fiber properties can be well outlined as following. Firstly, osmotic pressure caused by a $\mathrm{NaCl}$ concentration gap is one of the main factors that determines the poly(HIPE) fiber, and also has influence on its mechanical strength. Shrinkage happens when freeze drying the samples. Furthermore, adjusting the curing bath conditions has the potential to manipulate the poly(HIPE) fiber surface openness. A small open-celled fiber surface can be achieved by raising curing temperature, adding $\mathrm{NaCl}$ or adding initiator $\mathrm{NaPS}$ to the curing bath. In addition, NaPS added to the curing bath contributes to higher polymerization rate thus leads to more polymerization. In this latter case, a larger poly(HIPE) fiber diameter can then be expected. A fiber surface with large open cells can be achieved by adding PGS into the curing bath, for PGS generates large openness by attracting some amount of oil phase in HIPEs. A closed-cell surface on the poly(HIPE) fiber is produced with curing bath at $0.66 w t \% \mathrm{NaPS}$ at $85^{\circ} \mathrm{C}$ or $95^{\circ} \mathrm{C}$. 


\section{5-2: Future Works}

More considerations can be given to explore different kinds of poly(HIPE) fibers structures by changing the aqueous phase or oil phase components. As part of this study, we attempted to prepare a special HIPE with no initiator added in its aqueous phase. By polymerizing this kind of HIPE in a curing bath containing initiator, we were able to obtain a hollow fiber. However, the mechanical strength of the new hollow fiber was too low to test. It would be helpful to find new monomers or different type of salts to fabricate hollow poly(HIPE) fibers with higher mechanical strength. It would also be helpful to look for a new approach to characterize their mechanical strength. 


\section{Chapter 6: References}

[1] Lissant, K. J. "The geometry of high-internal-phase-ratio emulsions." Journal of colloid and interface science 22.5 (1966): 462-468.

[2] Cameron, Neil R. "High internal phase emulsion templating as a route to well-defined porous polymers." Polymer 46.5 (2005): 14391449.

[3] Silverstein, Michael S. "PolyHIPEs: Recent advances in emulsiontemplated porous polymers." progress in Polymer Science 39.1 (2014): 199-234.

[4] Silverstein, Michael S. "Emulsion-templated porous polymers: a retrospective perspective." Polymer 55.1 (2014): 304-320.

[5] Bergshoef, Michel M., and G. Julius Vancso. "Transparent nanocomposites with ultrathin, electrospun nylon-4, 6 fiber reinforcement." Advanced materials 11.16 (1999): 1362-1365. [6] Kim, Jong-sang, and Darrell H. Reneker. "Mechanical properties of composites using ultrafine electrospun fibers." Polymer composites 20.1 (1999): 124-131.

[7] Huang, Zheng-Ming, et al. "A review on polymer nanofibers by electrospinning and their applications in nanocomposites." Composites science and technology 63.15 (2003): 2223-2253.

[8] Frenot, Audrey, and loannis S. Chronakis. "Polymer nanofibers assembled by electrospinning." Current opinion in colloid \& interface science 8.1 (2003): 64-75. 
[9] Ramakrishna, Seeram, et al. "Electrospun nanofibers: solving global issues." Materials today 9.3 (2006): 40-50.

[10] Lu, Ping, and Younan Xia. "Maneuvering the internal porosity and surface morphology of electrospun polystyrene yarns by controlling the solvent and relative humidity." Langmuir 29.23 (2013): 7070-7078. [11] Casper, Cheryl L., et al. "Controlling surface morphology of electrospun polystyrene fibers: effect of humidity and molecular weight in the electrospinning process." Macromolecules 37.2 (2004): 573-578. [12] Chou, Wen-Li, Da-Guang Yu, and Ming-Chien Yang. "The preparation and characterization of silver-loading cellulose acetate hollow fiber membrane for water treatment." Polymers for advanced technologies 16.8 (2005): 600-607. [13] Bognitzki, Michael, et al. "Nanostructured fibers via electrospinning." Advanced Materials 13.1 (2001): 70-72. [14] Tadros, Tharwat F. Emulsion science and technology: a general introduction. Wiley-VCH Verlag GmbH and Co. KGaA: Weinheim, 2009. [15] Rayleigh, Lord. "XVI. On the instability of a cylinder of viscous liquid under capillary force." The London, Edinburgh, and Dublin Philosophical Magazine and Journal of Science 34.207 (1892): 145-154.

[16] Eggers, Jens. "Nonlinear dynamics and breakup of free-surface flows." Reviews of modern physics 69.3 (1997): 865. 
[17] Rutland, D. F., and G. J. Jameson. "A non-linear effect in the capillary instability of liquid jets." Journal of Fluid Mechanics 46.02 (1971): 267-271.

[18] Tadros, Tharwat F. Emulsion science and technology: a general introduction. Wiley-VCH Verlag GmbH and Co. KGaA: Weinheim, 2009. [19] Foudazi, Reza, et al. "Chemorheology of Poly (high internal phase emulsions)." Macromolecules 46.13 (2013): 5393-5396. [20] J van't Hoff, Jacobus. "The function of osmotic pressure in the analogy between solutions and gases." Proceedings of the Physical Society of London 9.1 (1887): 307.

[21] Amiji, Mansoor M., and Beverly J. Sandmann. Applied physical pharmacy. McGraw-Hill Medical, 2002. pp. 54-57. ISBN 0-07-135076-4. [22] Cath, Tzahi Y., Amy E. Childress, and Menachem Elimelech. "Forward osmosis: principles, applications, and recent developments." Journal of membrane science 281.1 (2006): 70-87. [23] Analyzer, OLI Stream. "2.0, OLI Systems Inc., Morris Plains, NJ, 2005."

[24] Taylor, P. "Ostwald ripening in emulsions." Advances in colloid and interface science 75.2 (1998): 107-163.

[25] Borwankar, Rajendra P., Lloyd A. Lobo, and Darsh T. Wasan. "Emulsion stability—kinetics of flocculation and coalescence." Colloids and surfaces 69.2 (1992): 135-146.

[26] Aronson, Michael P., and Michael F. Petko. "Highly concentrated 
water-in-oil emulsions: Influence of electrolyte on their properties and stability." Journal of colloid and interface science 159.1 (1993): 134-149. [27] White, Frank M. "Fluid mechanics, ed." (2003).

[28] Nakayama, Yasuki, and Robert Boucher. Introduction to fluid mechanics. Butterworth-Heinemann, 1998. 